\title{
Application of ANN in Pavement Engineering: State-of-Art
}

\section{Miguel Abambres}

Road Pavements Laboratory, Research Center for Territory, Transports and Environment, Department of Civil Engineering, University of Coimbra, Rua Luís Reis Santos, 3030-788, Coimbra, Portugal, abambres@ netcabo.pt; ORCID: 0000-0003-4107-8501

\section{Adelino Ferreira}

Road Pavements Laboratory, Research Center for Territory, Transports and Environment, Department of Civil Engineering, University of Coimbra, Rua Luís Reis Santos, 3030-788, Coimbra, Portugal, adelino@dec.uc.pt; ORCID: 0000-0002-1681-0759

\begin{abstract}
There has been much discussion about the impact and future of artificial intelligence (AI) in our lives and future generations. Many experts even believe that AI will "rule" the world. Artificial Neural Networks (ANN) have provided a convenient and often extremely accurate solution to problems within all fields, and can be seen as advanced general-purpose regression models that try to mimic the behavior of the human brain. The adoption and use of ANN-based methods in the Mechanistic-Empirical Pavement Design Guide is a clear sign of the successful use of neural nets in geomechanical and pavement systems. This work aims to provide an extensive and detailed state-of-the-art of the application of ANN models to pavement management, materials and design problems. Unlike former review articles published before 2014, this work is more descriptive and makes the review much more appealing to the reader by highlighting numerically and/or graphically the effectiveness and possible drawbacks of each ANN application.
\end{abstract}

Keywords: Artificial Intelligence; Artificial Neural Networks; Pavement Materials; Pavement Design; Pavement Distresses; Pavement Management.

\section{Introduction}

\subsection{Artificial Intelligence and Machine Learning}

There has been much discussion about the impact and future of artificial intelligence (AI) in our lives and future generations, and it has even been said by many experts that 
Abambres M, Ferreira A (2017). Application of ANN in Pavement Engineering: State-of-Art, hal-02066889

(C) 2017 by Abambres and Ferreira (CC BY 4.0)

AI will "rule" the world. But what exactly is AI? It has been defined in several ways based on the four approaches described below (Russell and Norvig 2010), namely (i) Thinking Humanly (Bellman 1978) - AI is the automation of activities that we associate with human thinking, such as decision-making, problem solving or learning, (ii) Thinking Rationally (Winston 1992) - AI is the study of the computations that make it possible to perceive, reason and act, (iii) Acting Humanly (Rich and Knight 1991) - AI is the study of how to make computers do things at which, for now at least, people are better, and (iv) Acting Rationally (Poole et al. 1998) - AI is The study of the design of intelligent agents.

Learning is central to human knowledge and intelligence, and, likewise, it is also essential for building intelligent machines. Years of work in AI have shown that trying to build intelligent computers by programming all the rules is unfeasible; thus, automatic learning is crucial. Machine learning is a set of tools that, broadly speaking, allow us to "teach" computers how to perform tasks by providing examples of how they should be done (Hertzmann and Fleet 2012) - basically, a machine learning system learns by experience. The world is quietly being reshaped by machine learning, and the most powerful form of it used today is called "deep learning", which builds a complex mathematical structure called an Artificial Neural Network (ANN) based on vast quantities of data (Hern 2016) (the term "neural net" is also used throughout this manuscript). All the biggest technology companies (e.g., Facebook, Microsoft, Skype, Google) rely on ANN-based technologies (Scott 2016). Other than machine learning, there are other AI techniques that allow machines to act human-like, and one of the firstly 
Abambres M, Ferreira A (2017). Application of ANN in Pavement Engineering: State-of-Art, hal-02066889

(C) 2017 by Abambres and Ferreira (CC BY 4.0)

employed is called Expert System (ES). For instance, in a rule-based ES, the knowledge and experience of the expert are coded as a series of if-then rules (Basheer and Hajmeer 2000). But what does the decision about which modelling technique (e.g., ANN, ES or theoretical / mechanistic modelling) to use in an arbitrary problem depend on? Primarily, on the availability of both the theory, explaining the underlying phenomenon, and the data. When the latter is abundant but there is unclear theory, machine learning techniques can be a perfect tool. Conversely, when both the data and theory are insufficient, an ES is normally sought. An illustration of the several possible scenarios is shown in Fig. 1 (shadowed areas represent regions where any of the contiguous tools might me used).

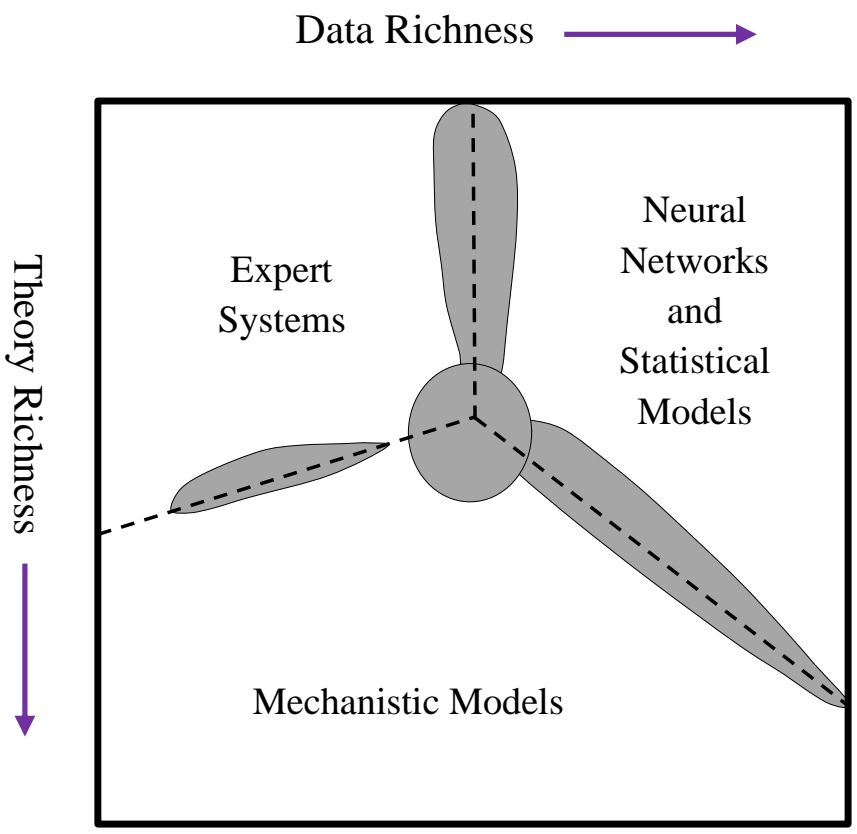

Fig. 1. Suitable techniques as function of theory/data richness (based on Basheer and Hajmeer 2000). 
Abambres M, Ferreira A (2017). Application of ANN in Pavement Engineering: State-of-Art, hal-02066889

(C) 2017 by Abambres and Ferreira (CC BY 4.0)

Although ANN is the oldest AI technique, whose initial development dates back to 1943 (McCulloch and Pitts 1943), it is still the leading application if one counts the number of practical applications (Wilamowski and Irwin 2011), such as Civil Engineering, Bioinformatics, Chemistry, Finances, Internet, Medicine, Organization and Management, Robotics, Speech Processing or Meteorology, just to name a few (Prieto et. al 2016). In its most general form, an ANN is a hardware or software "machine" designed to perform a particular task or function of interest based on the way the human brain processes information, i.e. with the help of its billions of processing units, the neurons. ANNs have been employed to perform several types of relevant "real-world" basic tasks, such as (i) classification, like ( $\left.i_{1}\right)$ sequence / pattern recognition, ( $\left.i_{2}\right)$ identification of new data, or $\left(i_{3}\right)$ decision-making, where the goal is to map each input with an output class, (ii) functional approximation / forecasting, (iii) clustering (grouping data into classes by analyzing the similarities or dissimilarities between input patterns), etc. - some of these tasks are illustrated in Fig. 2. Furthermore, ANNs have proven to be very competitive when compared to more popular data analysis methods, usually based on explicit statistical modeling. The work on ANN was and has been motivated by the recognition that the human brain computes in a totally different way when compared to the conventional digital computer. The brain is a highly complex, nonlinear and parallel processing system which has the capacity to perform certain computations (e.g., pattern recognition, perception, motor control) many times faster than the most powerful computer ever developed (Haykin 2009). Just like a nervous system, which needs to 
Abambres M, Ferreira A (2017). Application of ANN in Pavement Engineering: State-of-Art, hal-02066889

(C) 2017 by Abambres and Ferreira (CC BY 4.0)

evolve in order to adapt to the surrounding environment, ANNs need to go through an adaptation/learning process in order to perform well. ANNs can be seen as advanced general-purpose regression models that try to mimic the behavior of the human brain, although at present no ANN is anywhere near to recreating the complexity of the brain. However, the progress that has been made since their inception is remarkable, and it is certain that the development and applications of these algorithms will keep growing in the future (Flood 2008, Haykin 2009).

\subsection{Application of ANN in Civil Engineering}

Although genetic algorithms (GA) have often been employed successfully (e.g., Santos and Ferreira 2012, Jorge and Ferreira 2012, Santos et al. 2017, to cite some recent work from the second author), ES and ANN have been the most commonly used AI techniques in Civil Engineering since the latter's inception in the mid-1980s (Mosa et al. 2013). ANN have provided a convenient and often highly accurate solution to problems within all branches, appearing from the statistics on publications to be one of the great successes of computing (Flood 2008). The first journal article on civil engineering applications of neural networks 


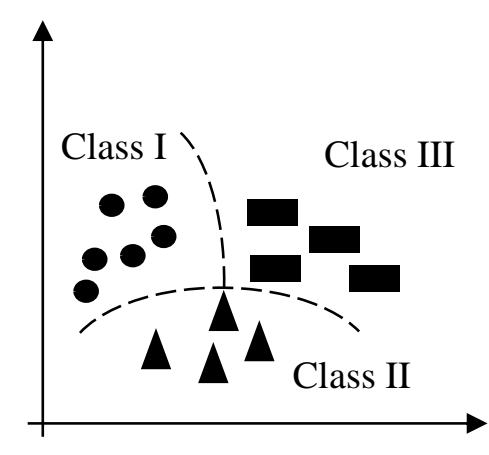

(a) pattern classification

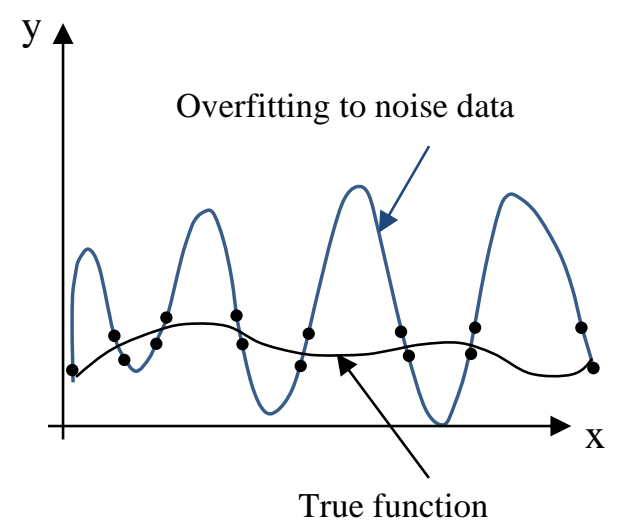

(c) functional approximation

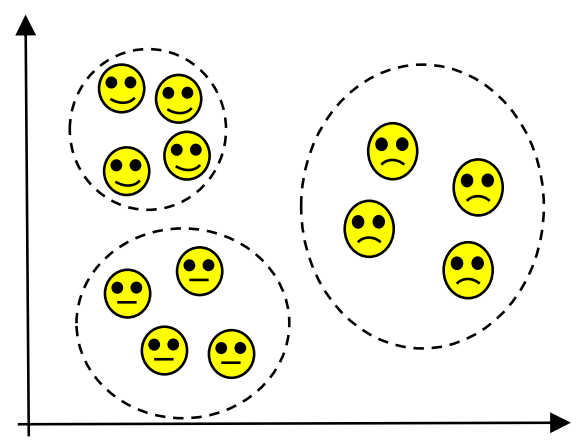

(b) clustering

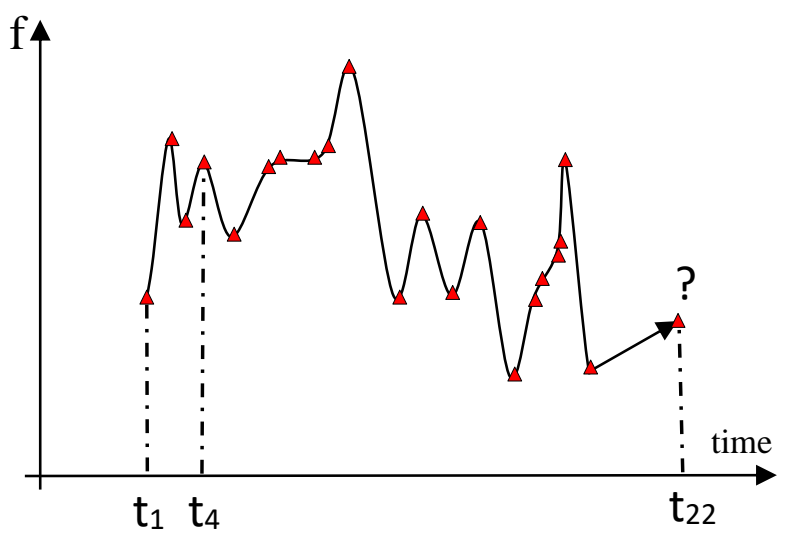

(d) forecasting

Fig. 2. Some typical problems solved by ANN (based on Basheer and Hajmeer 2000).

was published by Adeli and Yeh (1989). Since then, many other applications of ANN within all fields of Civil Engineering have arisen with increased complexity and sophistication (Adeli 2001). Because of their much faster response in comparison to FEA, they are often used in approximation for structural analysis (in particular, parametric analysis can then be performed without spending so much time), as well as in the active control of structures (Sheidaii and Bahraminejad 2012). Areas like (i) buckling and bearing capacity prediction 
Abambres M, Ferreira A (2017). Application of ANN in Pavement Engineering: State-of-Art, hal-02066889

(C) 2017 by Abambres and Ferreira (CC BY 4.0)

(e.g., Sharifi and Tohidi 2014b), (ii) constitutive modeling (e.g., Oeser and Freitag 2016), (iii) structural reliability and/or optimization (e.g., Papadrakakis and Lagaros 2016), (iv) structural health monitoring (e.g., Min et al. 2012), or (v) transportation engineering (e.g, Dougherty 1995, Flintsch et al. 2004, Kim et al. 2009, Ceylan et al 2014, Alkheder et al 2016), have all received special focus. The adoption and use of ANN-based methods in the MechanisticEmpirical Pavement Design Guide (NCHRP 2004) is a clear sign of the successful use of neural nets in geomechanical and pavement systems.

\subsection{Aim}

Due to (i) the extent of ANN-based applications in pavement engineering since the 1990`s, and (ii) the rising potential of neural nets to the performance of more accurate and efficient engineering, this work aims to provide an extensive and detailed state-of-the-art application of ANN models in the design and management of pavements. Unlike previous review articles published on these topics before 2014 (Dougherty 1995, Flintsch et al. 2004, Kim et al. 2009, Ceylan et al 2014), it is worth noting that the present work is far more descriptive and makes the review much more appealing to the reader by highlighting numerically and/or graphically the effectiveness and possible drawbacks of each ANN application.

After briefly addressing the ANN features and fundamentals in the next section, the applications of neural nets to several types of pavement problems are described in detail in section 3 . 


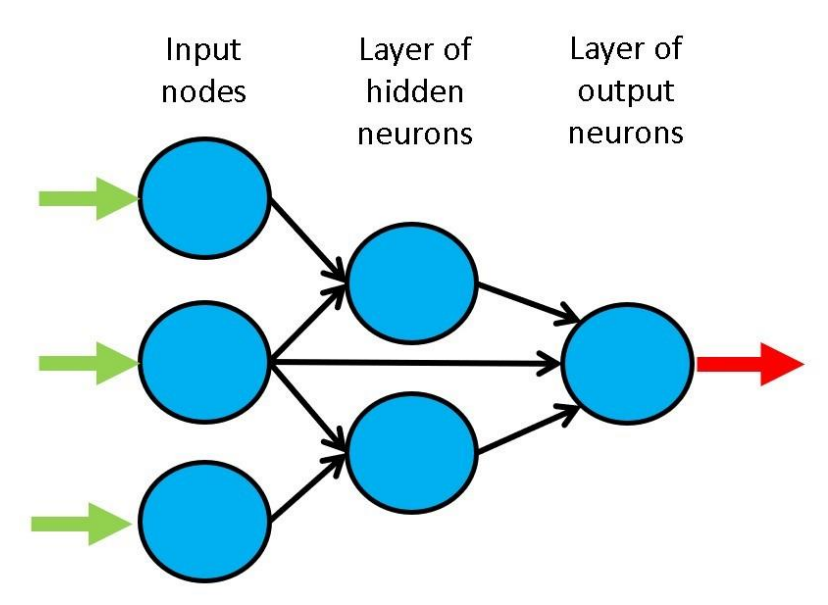

Fig. 3. Example of a Multi-Layer Feedforward Network.

\section{Brief Overview of ANN Features and Fundamentals}

This section addresses the main neural network features and gives a short overview about the main concepts inherent to the most typical ANN models employed in pavement engineering so far. Further details about virtually any topic regarding ANN can be found in well-known books like Haykin (2009) or Du and Swamy (2014).

The general ANN structure can be seen as several partially or fully connected processing units (neurons), which are disposed in several vertical layers (the input layer, hidden layers - if there are some, and the output layer), as illustrated in Fig. 3. Associated to each neuron is a linear or nonlinear transfer (also called activation), function, which receives an input and transmits an output - a typical neuron's model is described in 2.1. Each connection (link between two nodes in the network), is associated to a synaptic weight, which is a typical example of a network unknown to be determined during the network design process. The ANN's computing power, making them suitable for efficiently solving complex (small to 
Abambres M, Ferreira A (2017). Application of ANN in Pavement Engineering: State-of-Art, hal-02066889

(C) 2017 by Abambres and Ferreira (CC BY 4.0)

large-scale), intractable problems, can be attributed to their (i) massive parallel distributed structure and (ii) ability to learn and generalize, i.e, produce reasonably accurate outputs for inputs not used during the training phase. Besides, neural networks offer the following useful features:

(i) Nonlinearity: guaranteed when at least one neuron's transfer function is nonlinear.

(ii) Input-output mapping: in the context of nonlinear vector mapping problems comprising a fixed set of independent variables, ANN-based solutions are frequently more accurate than the ones provided by traditional approaches (e.g., multi-variate nonlinear regression), despite the fact they do not require a good knowledge of the function shape being modeled (Flood 2008).

(iii) Adaptivity: a neural network trained to operate in a specific environment can be easily retrained to deal with minor changes in that environment (e.g., when operating in a nonstationary environment).

(iv) Ability to handle imprecise / noisy and/or missing data (Basheer and Hajmeer 2000).

The way in which the neurons of a neural net are structured and linked define what is known as the network architecture. In general, one may identify three fundamentally different classes of network architectures: (i) Single-Layer Feedforward Network, (ii) Multi-Layer Feedforward Network, and (iii) Recurrent Networks (RNN) (Haykin 2009). In sub-section 2.2, the multi-layer perceptron (MLP) is briefly addressed since it is the most commonly used network type in pavement engineering applications. 
Abambres M, Ferreira A (2017). Application of ANN in Pavement Engineering: State-of-Art, hal-02066889

(C) 2017 by Abambres and Ferreira (CC BY 4.0)

\subsection{Model of a Neuron}

Each processing unit (sometimes called computation node) of an ANN is called a neuron, and it plays a crucial role in the network's behavior. There are three basic elements in a typical model of a neuron, as depicted in Fig. 4: (i) connecting links (also called synapses) between each "input" signal $\left(x_{j}, j=1, \ldots, J\right)$ and the $k^{\text {th }}$ neuron, which are characterized by their synaptic weights $\left(w_{j k} \in R\right)$, (ii) a summing junction $\left(s_{k}=x_{j} w_{j k}\right)-$ Einstein summation convention employed, to add up the weighted input signals that converge to the neuron, and (iii) an activation (or transfer) function $\varphi_{k}$, which receives $s_{k}$ plus neuron's bias $\left(b_{k} \in R\right)$ as input - also known as the induced local field, and provides neuron's output $y_{k}$. In ANN design, the activation functions are user-defined (e.g., logistic, linear).

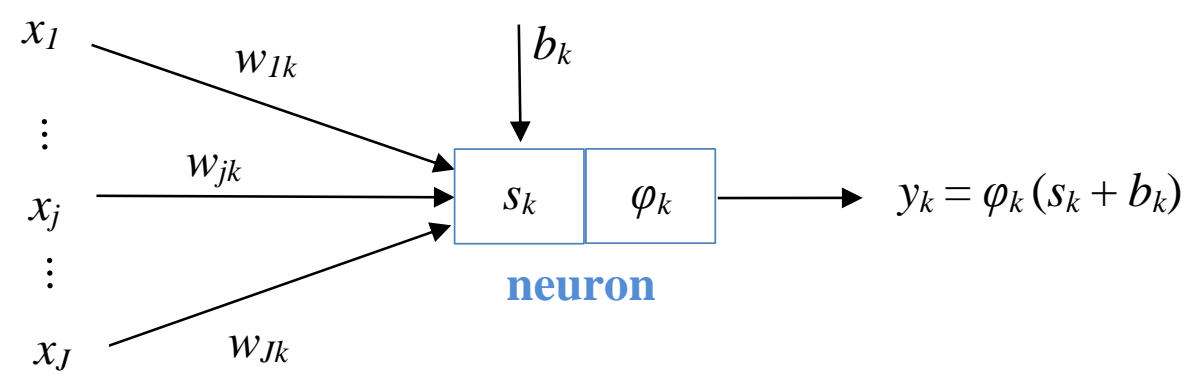

Fig. 4. A typical model of a neuron. 
Abambres M, Ferreira A (2017). Application of ANN in Pavement Engineering: State-of-Art, hal-02066889

(C) 2017 by Abambres and Ferreira (CC BY 4.0)

\subsection{The Multi-Layer Perceptron (MLP)}

This is a feedforward ANN, i.e. the signal flow through the network progresses in a forward direction from left to right, and on a layer-by-layer basis, and exhibits at least two neuron-based layers and the input node layer. Each layer of neurons that is not the output layer is called a "hidden layer" and the corresponding units are called "hidden neurons". By adding one or more hidden layers, the network is enabled to extract higher-order statistics from its input (Haykin 2009). Fig. 3 represents a 3-layer feedforward network, also referred to as 3-4-2 (3 input nodes, 4 hidden neurons in the single hidden layer, and 2 output neurons). As can be seen, each node in each layer links to every node in the next layer (typically called a fully-connected network), i.e. the output signals of the $2^{\text {nd }}$ (hidden) layer will serve as input signals of the $3^{\text {rd }}$ (output) layer - unless stated otherwise (e.g., PC - partially connected), all MLP networks mentioned in this paper are fully-connected. Nodes in each layer do not connect to each other and no connections across layers (between the input and output layers, in this case) are allowed. The synaptic weights and bias mentioned in 2.1 are network unknowns to be computed through the learning process, which is addressed next.

\subsection{Knowledge and Learning}

In ANN, as in any other machine learning technique, a good solution depends on a good representation of knowledge (Woods 1986), which makes the development of such networks a real design challenge. For a specified network architecture, that knowledge representation is defined by the values taken on by the free parameters (or unknowns) of 
Abambres M, Ferreira A (2017). Application of ANN in Pavement Engineering: State-of-Art, hal-02066889

(C) 2017 by Abambres and Ferreira (CC BY 4.0)

the network (e.g., synaptic weights and bias), which are determined by a major task for any ANN, called Learning. This stage typically consists of two phases: (i) training and (ii) validation. From the obtained knowledge, examples (also known as "data points" or "training set") are selected to train the neural network. These examples are said to be "labeled" or "unlabeled", depending on whether they represent an input paired with the target output (desired "response") or just the input itself - in most cases addressed so far in pavement engineering, the performed learning is called "supervised", since all the examples considered are "labeled". One of the convergence criterion most often employed in the design of ANNs is called "early stopping", and it is a cross-validation of the network performance during training. This means, as Fig. 5 suggests, that while the network performance measure (e.g., average relative error of all output values) is computed and stored after each training iteration, a completely different data set (often smaller) is used for (cross-)validation purposes (not training) and the corresponding performance measure after each iteration is determined and stored. Whereas the trainingbased performance curve usually decreases monotonically during training, the crossvalidation counterpart most often exhibits a global minimum after a certain amount of iterations, as shown in Fig. 5. That singularity is called early-stop, and heuristics suggests it be used as the stop point in neural network training. In order to assess if the first minimum found is local or global, one should keep increasing the amount of iterations according to some trade-off between training time and generalization ability. In particular, if the validation curve keeps decreasing monotonically after a significant (user- 
Abambres M, Ferreira A (2017). Application of ANN in Pavement Engineering: State-of-Art, hal-02066889

(C) 2017 by Abambres and Ferreira (CC BY 4.0)

defined) amount of training, one should define thresholds for the validation and training performance values. At this point, after the "optimum" network parameters are defined, some authors (e.g., Fonseca et al. 2003) still perform a final assessment of the model quality by evaluating its results for a third distinct data set called "testing set".

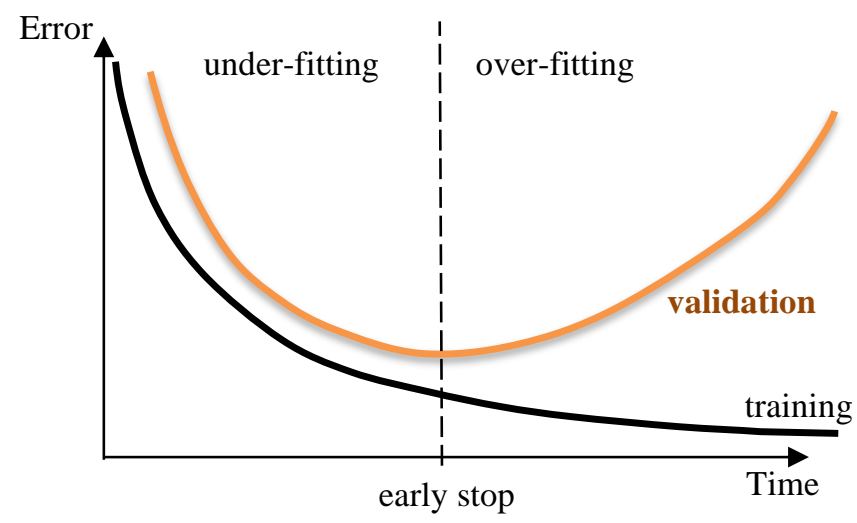

Fig. 5. Cross-validation in training - ANN generalization ability.

Among the most popular training techniques that can be employed to get the neural network free parameters (or unknowns), namely the Back-Propagation (BP) and the Levenberg-Marquard (LM) algorithms, the most effective and robust is the latter (Wilamowski and Yu 2010a, b). More recently, a new algorithm called Extreme Learning Machine (ELM) was proposed by Huang et al. (2006a, b) and since its inception several variants / improvements of it have been proposed in the literature (e.g., Liang et al. 2006, Huang and Chen 2007, Miche et al. 2010, Huang et al. 2011). In the authors'opinion, ELM is quite easy to implement and is the most powerful of all training methods developed so far. However, it hasn't been applied in pavement engineering because it might not be implemented in commercial machine learning codes yet. 
Abambres M, Ferreira A (2017). Application of ANN in Pavement Engineering: State-of-Art, hal-02066889

(C) 2017 by Abambres and Ferreira (CC BY 4.0)

\subsection{The Universal Approximation Theorem}

For a nonlinear input-output mapping, this theorem states (Haykin 2009) that a single hidden layer MLP, with (i) any bounded, monotone-increasing and continuous activation function for the hidden neurons, and (ii) an identity (linear) transfer function for the output neurons, is sufficient to compute an arbitrarily good approximation of any continuous function in a general n-dimensional space - the absolute difference between any estimated and target outputs can be less than any $\varepsilon>0$, for all input space values. However, it is worth recalling that this theorem does not guarantee great network behavior for learning time and/or generalization.

\subsection{Data Pre-Processing and Tuning of Network Layout}

In order to get the most out of the neural network abilities, it is highly recommended that the data is correctly selected and pre-processed before learning starts. To that end, there are several approaches worth considering, such as (i) input variable selection algorithms (e.g., May et al. 2011), (ii) dimensional analysis (e.g., Bhaskar and Nigam 1990), (iii) dimensionality reduction techniques (e.g., principal component analysis) (e.g., May et al. 2011), and (iv) normalization (e.g., Flood and Kartam 1994a, Azoff 1994).

A rule of thumb for obtaining good generalization in systems trained by examples is that one should use the smallest system that will fit the data (Reed 1993, May et al. 2011). Several guidelines - mostly (if not all) obtained from trial and error, (i) for choosing an 
Abambres M, Ferreira A (2017). Application of ANN in Pavement Engineering: State-of-Art, hal-02066889

(C) 2017 by Abambres and Ferreira (CC BY 4.0)

adequate initial number of hidden neurons/layers and also (ii) for network pruning (size reduction - nodes and/or connections), are available from many sources (e.g., Mozer and Smolensky 1989, Weigend et al. 1991, Reed 1993, Basheer and Hajmeer 2000, Rafiq et al. 2001, Olden and Jackson 2002).

\section{ANN Applications in Pavement Engineering}

\subsection{Pavement Management}

\subsubsection{Pavement Distresses}

\section{Roughness}

A pavement profile (also called roughness) is one of the most effective vehicle environmental conditions that influences ride, handling, fatigue, fuel consumption, tire wear, maintenance costs and vehicle delay costs.

Roberts and Attoh-Okine (1998) compares the use of two ANN models to predict roughness based on pavement condition characteristics and traffic. The study uses 105 data points characterized by 11 variables of 5 types (rutting, fatigue cracking, transverse cracking, block cracking, equivalent axle loads and the international roughness index (IRI)), with IRI being the target variable of the problem and the others the input counterpart. From that dataset, 75 examples were taken for training purposes and 30 for validation. One of the proposed neural net is a BP-based 10-5-1 MLP, and the comparison model is called quadratic function ANN. It is a feedforward net exhibiting a generalized adaptive architecture, which uses a combination of supervised and self-organized (unsupervised) learning. This type of network uses an evolutionary mechanism to fit the problem at hand 
Abambres M, Ferreira A (2017). Application of ANN in Pavement Engineering: State-of-Art, hal-02066889

(C) 2017 by Abambres and Ferreira (CC BY 4.0)

and does not require the modeler to specify the number of layers / nodes. It was shown that the latter model $\left(\mathrm{R}^{2}=0.74\right)$ outperforms the traditional MLP network $\left(\mathrm{R}^{2}=0.57\right)$.

Yildirim and Uzmay (2001) employed a BP-based 1-20-3 Radial Basis Function neural net (RBFNN) using Gaussian transfer functions for the prediction of vehicle's acceleration amplitudes. Velocities of the vehicle are used as inputs of the network, and training was performed using a dataset of 80000 instances. The method was successfully employed to predict random vibration theory results.

Choi et al. (2004) developed an ANN for the prediction of IRI values using a BP-based 6-10-1 MLP network. In order to determine the network topology resulting in acceptable performance, several nets were designed by increasing hidden nodes 1 by one from 1 to 15. Ninety-two data points were considered in learning, 25 of which were set aside for validation purposes. Yielded results indicate that the designed network can be effectively used in pavement performance prediction.

Yousefzadeh et al. (2010) developed a LM-based x-6-6-4 RNN (no. of input nodes not clear) for the prediction of pavement profiles of a vehicle's four wheels (4 outputs). In addition to the vehicle's accelerations, the profiles themselves were also input (network feedback). It was shown that ANN estimated the pavement profiles quite reasonably.

Solhmirzaei et al. (2012) developed a truly accurate model for the prediction of pavement profiles making use of a BP-based x-15-4 Wavelet Neural Network (WNN). The inputs were accelerations of a vehicle moving along a road and the outputs were vertical displacement profiles of each vehicle wheel during the trip. 
Abambres M, Ferreira A (2017). Application of ANN in Pavement Engineering: State-of-Art, hal-02066889

(C) 2017 by Abambres and Ferreira (CC BY 4.0)

An ANN-based prediction of road profiles has been demonstrated by Ngwangwa et. al (2014), who developed a LM-based 3-50-50-2 MLP network trained with 3964 data points obtained numerically. Validation was carried out using measured data. The results show very good correlations, even over discrete obstacles.

Ziari et al (2016) proposed an ANN to predict IRI values in the short- and long-term for flexible pavements. Sensitivity analysis using several LM-based MLP networks was performed, parameterizing the number of hidden layers (1 to 3 ) and nodes (3 to 100) in order to find an optimal model. From the databank used in learning (205 data points), 154 samples were used in training, 41 in validation and 10 in testing. It was concluded that ANN models predict the future of pavement condition with satisfactory accuracy in the short- and long-term. Whereas (i) the best performance regarding the first category (short term) was obtained for the topology 9-80-50-30-1, (ii) structure 9-3-1 yielded the best performance in the second category (short term), and (iii) 9-8-1 proved to be the best layout in the third category (long term). Even so, layouts like 9-5-1, 9-7-1, 9-20-1 and 950-1 exhibited MAPE $<10 \%$ and $\mathrm{R}^{2}>0.9$ for the testing set.

\section{Skid Resistance}

It is well known that weather and traffic influence the degradation of skid resistance between the tire and pavement surface over time. 
Abambres M, Ferreira A (2017). Application of ANN in Pavement Engineering: State-of-Art, hal-02066889

(C) 2017 by Abambres and Ferreira (CC BY 4.0)

Owusu-Ababio (1995) implemented an ANN to predict skid resistance of flexible pavements in order to assess future rehabilitation needs. Only original bituminous concrete pavements with no overlays were considered. The data used were 45 observations for training and 15 for validation, featuring (i) skid number (output or target variable), (ii) pavement surface age, (iii) pavement regional location, (iv) accumulated AADT (Annual Average Daily Traffic) and (v) posted speed limit. A partially connected 4-3-2-1 MLP was employed, as shown in Fig. 6. The software used to design the ANN (Autonet) uses adaptive modeling procedures - the basic approach is that (i) exactly two nodes must connect to any neuron in the next layer and (ii) the number of layers and neurons per layer are limited once the network performance gets worse. It was observed that the ANN validation error is much lower than that obtained from the linear regression approach.

Bosurgi and Trifirò (2005) developed a neural net-based "sideway force coefficient" prediction model to be applied on a motorway. The database included 713 samples, from which 463 were selected at random for training and the remainder for validation. A LM-based 2-3-1 MLP was adopted. The results confirmed that the neural network had interpreted the phenomenon well, since an error inferior to $7 \%$ was observed in $91 \%$ of the cases in the training phase and $86 \%$ in the validation phase. 


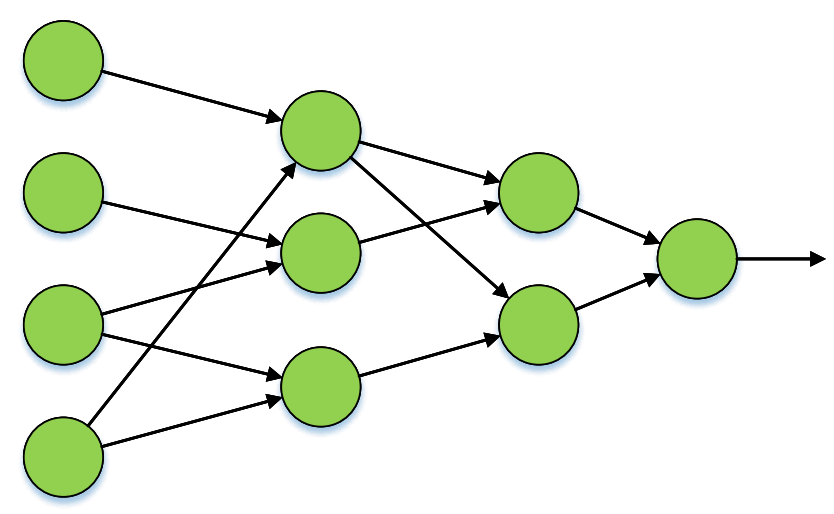

Fig. 6. ANN final layout in Owusu-Ababio (1995).

\section{Cracking}

Cracking is one of the primary forms of distress in hot-mixed asphalt pavements. In recent years, Paris' law, which is based on linear elastic fracture mechanics, has been adopted to analyze pavement cracking problems. However, one of the drawbacks of this model regards the quick and accurate computation of the stress intensity factors (SIF), a parameter that amplifies the magnitude of applied stress, at crack tips. Finite element analysis (FEA) is a powerful tool for that purpose, but the $3 \mathrm{D}$ pavement behavior can only be accurately predicted using 3D FEA, and unfortunately that computation is still too heavy (slow) when using today's available resources in practical applications.

Kaseko (1993) proposed an ANN for automatic detection, classification and quantification of pavement surface cracking, based on processing pavement images. Pavement cracks can accurately be classified by type (e.g., transverse, longitudinal, alligator and block), severity and extent. For that purpose, binary images are divided into tiles and each tile is analyzed to determine the existence and orientation of any crack in 
Abambres M, Ferreira A (2017). Application of ANN in Pavement Engineering: State-of-Art, hal-02066889

(C) 2017 by Abambres and Ferreira (CC BY 4.0)

it. A BP-based 5-5-5 MLP was used for this task. Twenty images were selected for training and validation purposes. Overall, the neural net classified more than $96 \%$ of the tiles in the training images and $93 \%$ in the validation counterpart.

Owusu-Ababio (1998) developed an ANN for the prediction of flexible pavement cracking. In learning, 60 observations were split into 45 for training and 15 for validation. Network architecture was determined by trial-and-error by variation of the amount of hidden units (in a single hidden layer) from 2 to 12 in unitary increments. The BP-based 3-5-1 MLP network was found to be optimal and yielded satisfactory results.

Due to limitations in traditional destructive and non-destructive testing approaches for the determination of surface-initiated fatigue crack depths, Mei et al. (2004) proposed an ANN for that purpose. A total of 1074 data points were collected from 75 road sections, from which 430 were used in training, 430 in validation and 214 in testing. Parametric analysis on the number of hidden layers/nodes and the learning algorithm showed that a LM-based 8-10-8-1 MLP yields the best performance - reasonably accurate results were obtained.

Lee (2004) presented three ANN to classify crack types from digital pavement images, as an alternative to pixel-based ANN (higher processing time), designated as image-based (INN), histogram-based (HNN) and proximity-based (PNN). Each model has a different number of input nodes and each output neuron represents a crack type. Several different three-layered BP-based MLP networks were explored with a different number of hidden nodes $(30,60,90,120,150)$ in order to find an optimal layout. The best performance was obtained with architectures 180-90-5 (INN), 27-60-5 (HNN) and 3-150-3 (PNN). Each 
Abambres M, Ferreira A (2017). Application of ANN in Pavement Engineering: State-of-Art, hal-02066889

(C) 2017 by Abambres and Ferreira (CC BY 4.0)

model was trained using 300 artificial images, and validated using 124 real and 150 artificial images. The INN is similar to the pixel-based neural net except that it uses crack tiles. The matrix of crack tiles ( 1 if there is crack, 0 it there isn't) is injected into the ANN input layer as an array with 180 binary values (12 rows x 15 columns in the "tiled" digital image) - inputs are read sequentially from the upper left corner tile to the bottom right corner tile, as illustrated in Fig. 7. HNN networks inject two histogram arrays into input layer (27 nodes - 12 for the horizontal histogram and 15 for the vertical counterpart), as illustrated in Fig. 8. PNN nets' input layer is defined by three variables, which, to be determined, requires computing the following quantities: (i) vertical proximity $\left(P_{v}\right)$, defined as

$$
P_{v}=\sum_{i=1}^{N c-1}\left|H_{v[i+1]}-H_{v[i]}\right|
$$

where $H_{v}$ is the vertical histogram and $N_{c}$ the number of columns of the "tiled" image, (ii) horizontal proximity $\left(P_{h}\right)$, defined as

$$
P_{h}=\sum_{i=1}^{N r-1}\left|H_{h[i+1]}-H_{h[i]}\right|
$$

where $H_{h}$ is the horizontal histogram and $N_{r}$ the number of rows of the "tiled" image, and (iii) the number of cracked tiles in the image. The final results indicate that the PNN produced the best result, with a $95.2 \%$ accuracy on real validation images, despite its simpler structure with the lesser computing requirement (INN and HNN corresponding performances were $70.2 \%$ and $75 \%$, respectively). 
Abambres M, Ferreira A (2017). Application of ANN in Pavement Engineering: State-of-Art, hal-02066889

(C) 2017 by Abambres and Ferreira (CC BY 4.0)

Ceylan et al. (2011) successfully used ANNs to model the stress intensity factor (SIF) as cracks grow upward through a hot mix asphalt overlay due to thermal effects. Numerical estimation of SIFs in front of a crack tip is traditionally obtained via FEA. The database of SIFs was modeled with 6 separate BP-based MLP ANNs exhibiting the following layouts and learning datasets: 8-40-40-1 (training=2990, validation=250), 840-40-1 (training=2990, validation=250), 8-40-40-1 $($ training $=2990$, validation $=250), 9$ 40-40-1 (training=1681, validation=250), 7-40-40-1 (training=1064, validation=250), 940-40-1 (training=871, validation=250). The results obtained are nearly perfect, as can be attested by Fig. 9 for the $1^{\text {st }}$ model.

Thube (2012) suggested appropriate ANNs to predict the progression of different pavement distresses. ANN model outputs included total cracking area (\%), total raveling area $(\%)$, total rut depth progression $(\mathrm{mm})$, and total roughness progression (IRI). For each pavement deterioration type a different ANN was proposed. For $\{$ training, validation, testing $\}$ datasets used in learning, there are (i) $\{228,57,20\}$ examples for cracking, (ii) $\{228,57,20\}$ examples for raveling, (iii) $\{247,70,25\}$ examples for rut depth, and (iv) $\{$ not disclosed, 70, 25\} examples for roughness. Sixteen BP-based MLP architectures were assessed (2-3 hidden layers, 4-7 hidden nodes) and models corresponding to the best performance were selected. Fig. 10 shows the evolution of performance measures as a function of the ANN topology used for the raveling progression models. The best ANNs exhibit the following layouts: (i) 26-7-7-7-1 (cracking), (ii) 26-5-5-1 (raveling), (iii) 29-77-7-1 (roughness), (iv) 31-6-6-1 (rut-depth). 
Abambres M, Ferreira A (2017). Application of ANN in Pavement Engineering: State-of-Art, hal-02066889

(C) 2017 by Abambres and Ferreira (CC BY 4.0)

Wu et al. (2014) developed neural network models to estimate SIFs at fatigue and reflective cracking, in order to remedy the lack of precision of multivariate regression models and the computation burden of FEA. Around 2 million crack SIFs on various pavement structures under different traffic loads were gathered from semi-analytical FEA. Eight and 32 ANN models were developed for fatigue and reflective crack prediction, respectively. Each of the former models made use of 36750 data points (29400 for training), whereas the latter used either 43200 (34560 for training) or 57600 (46080 for training) samples each. Several LM-based MLP topologies were investigated for every neural net model and the results showed that 7-60-60-1 (fatigue cracking) and 9-60-60-1 (reflective cracking) layouts yield the best performance. Besides the fact that ANN models are quite efficient in getting results once designed (> 30000 cases in less than a second), it also was shown that their performance clearly surpasses the nonlinear regression counterpart.

Gajewski and Sadowski (2014) proposed a FEA-ANN system, based on BP-based 4-7-2 MLP network and 4-5-2 RBFNN for the prediction of crack sensitivity in a subgrade layer. Input variables included asphalt pavement layer parameters and different load modes, and the expected output response would predict crack occurrence. FEA results were used as learning data (quantity not disclosed). The MLP performed far better than the RBFNN in the classification task, having yielded accuracies of (i) $94 \%$ vs. $65 \%$ in learning, (ii) $98 \%$ vs. $62 \%$ in validation and (iii) $92 \%$ vs. $77 \%$ in testing, respectively.

Yoo and Kim (2016) proposed a BP-based 8-12-8-2 MLP network to distinguish pavement cracks from noise objects in pavement images. Datasets consisting of 7075 and 
Abambres M, Ferreira A (2017). Application of ANN in Pavement Engineering: State-of-Art, hal-02066889 (C) 2017 by Abambres and Ferreira (CC BY 4.0)

10607 examples were used for training and validation, respectively, and the model demonstrated highly accurate prediction ability $(99.9 \%)$.

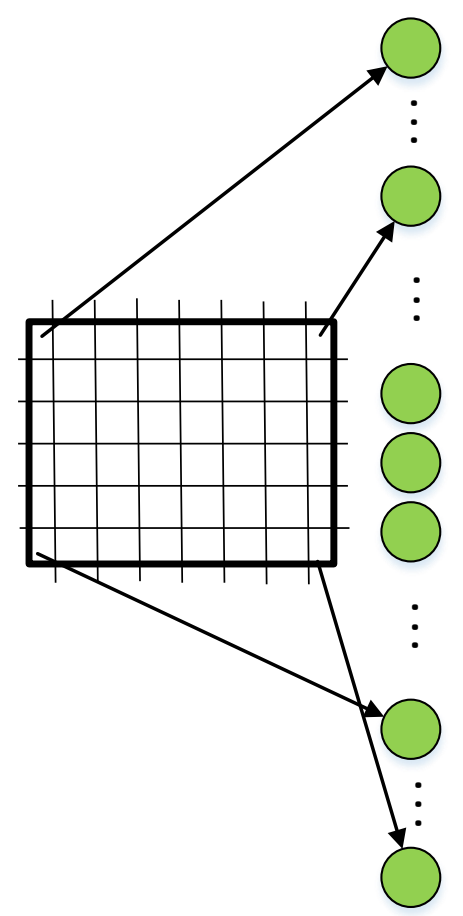

Fig. 7. Image-based neural network input layer (based on Lee 2004).

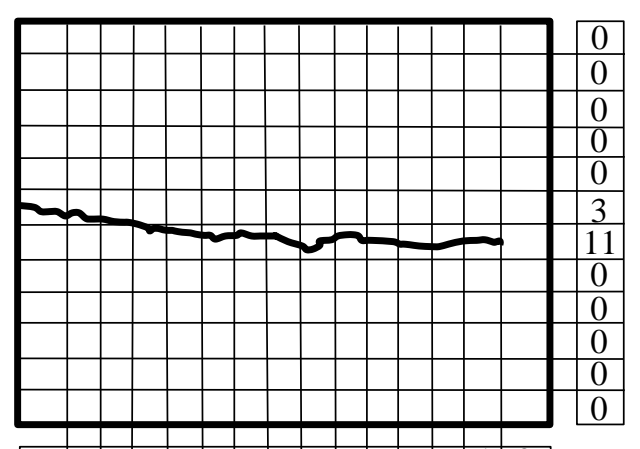

(a)

(b)

Fig. 8. HNN (a) vertical and (b) horizontal histogram (Lee 2004). 


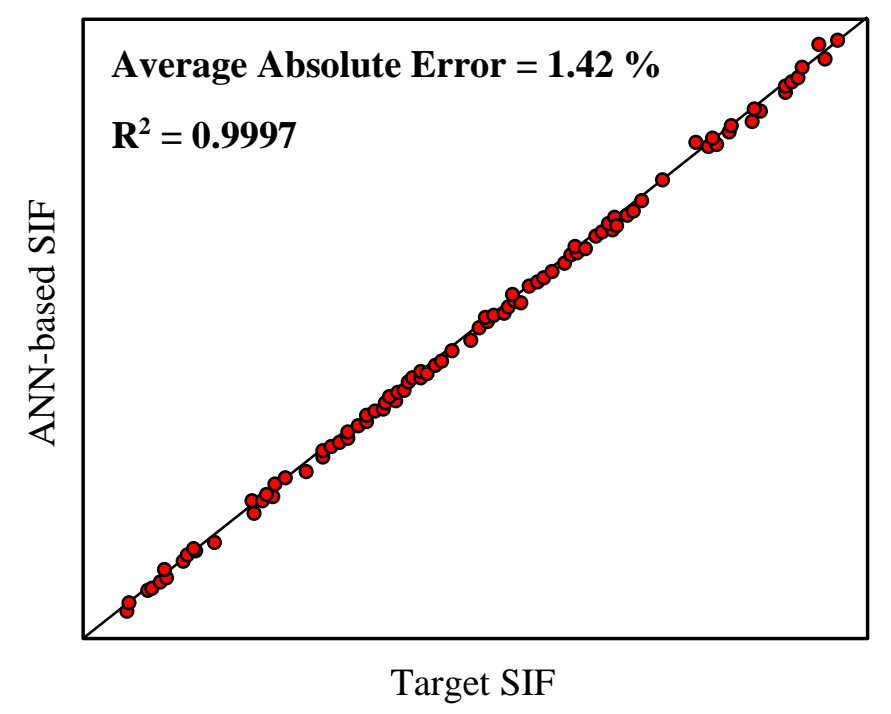

Fig. 9. ANN performance - AC overlay over AC (low slip interface) (based on Ceylan et al. 2011).

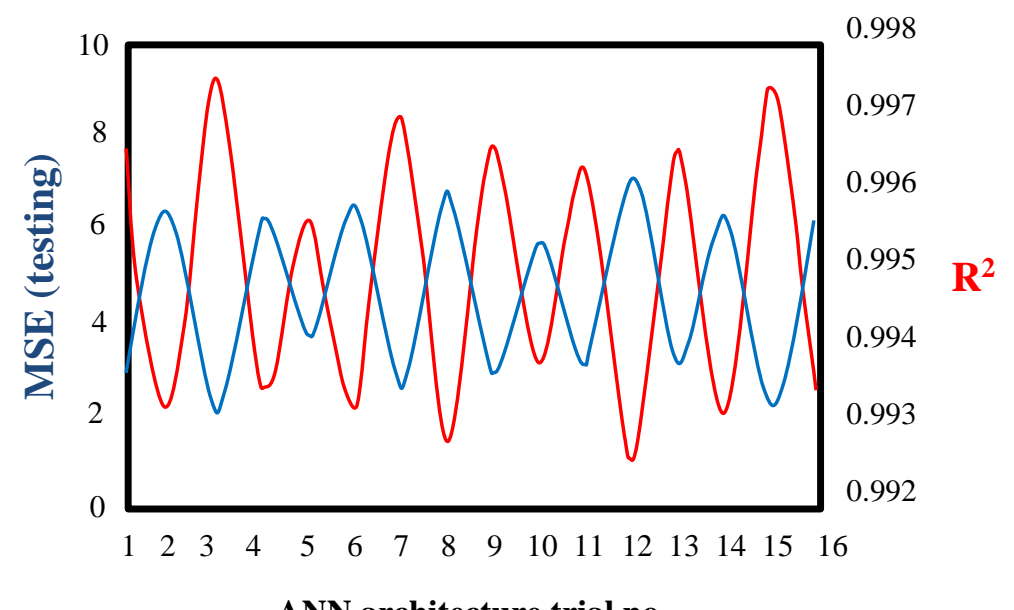

ANN architecture trial no.

Fig. 10. Variation in MSE and $R^{2}$ for the ravelling progression ANN models (based on Thube 2012). 
Abambres M, Ferreira A (2017). Application of ANN in Pavement Engineering: State-of-Art, hal-02066889

(C) 2017 by Abambres and Ferreira (CC BY 4.0)

\section{Joint Faulting}

Transverse joint faulting is one of the main types of distresses in jointed Portland cement pavements. It can be defined as the difference in elevation between adjacent slab edges at a transverse joint.

Saghafi et al. (2009) applied an ANN to estimate the effect of base layer conditions and pavement age on transverse joint faulting. For the databank used, 405 random observations were taken (250 for training, 75 for validation and 80 for testing). Several BP-based MLP networks were assessed parametrically in order to find the optimal layout, which was 8-8-8-1. The proposed ANN was able to successfully predict the measured joint faulting with $\mathrm{R}^{2}=0.94$ for the testing set. However, there are significant relative errors concerning small value faulting, especially for the testing set.

\subsubsection{Pavement Condition Indexes}

Present Serviceability Index (PSI) / Ratio (PSR)

Prediction modelling of pavement deterioration (a stochastic and nonlinear phenomenon) is crucial for an effective PMS, where the goal is to find the appropriate period and method of rehabilitation.

Banan and Hjelmstad (1996) proposed an algorithm called Monte Carlo Hierarchical Adaptive Random Partitioning (MC-HARP) that produces a model that can be classified as a neural network. The authors showed that a model of that type can be constructed for AASHO road-test data in order to compare the results with the AASHO formula. The training set contains 6192 data points and the validation counterpart has 6762 samples. Five input 
Abambres M, Ferreira A (2017). Application of ANN in Pavement Engineering: State-of-Art, hal-02066889

(C) 2017 by Abambres and Ferreira (CC BY 4.0)

variables (surface, base and subbase thicknesses, axle load and the logarithm of accumulated single axle load applications) and one output variable (PSI) were considered. It was concluded that the neural net-type MC-HARP model outperforms the AASHO formula in the determination of PSI.

Terzi (2007) developed an ANN for the estimation of PSR values. Dataset taken from AASHO test results includes 74 samples, from which 59 and 15 were used for training and validation, respectively. Several topologies were tested but the LM-based 5-4-1 MLP appeared to be the most suitable. It was concluded that the ANN model produces better results than PSI equation when predicting the AASHO panel data for both training $\left(\mathrm{R}^{2}(\mathrm{PSI})\right.$ $\left.=0.83 ; \mathrm{R}^{2}(\mathrm{ANN})=0.99\right)$ and validation $\left(\mathrm{R}^{2}(\mathrm{PSI})=0.82 ; \mathrm{R}^{2}(\mathrm{ANN})=0.87\right)$ sets.

Tabatabaee et al. (2013) proposed a two-stage soft computing model to properly classify (using a support vector classifier - SVC) and accurately predict pavement performance. A PC LM-based 8-5-1 RNN is used for the second stage to predict performance in terms of PSI, as illustrated in Fig. 11. The database used in learning involves 14 mainline AC test cells. Three cells were used for testing purposes. The two-stage model results were compared with those yielded from a RNN-based single model, and it was concluded that the latter was less effective in the prediction of PSI values $\left(\mathrm{R}^{2}=0.95\right.$ vs. $\left.\mathrm{R}^{2}=0.98\right)$. 
Abambres M, Ferreira A (2017). Application of ANN in Pavement Engineering: State-of-Art, hal-02066889

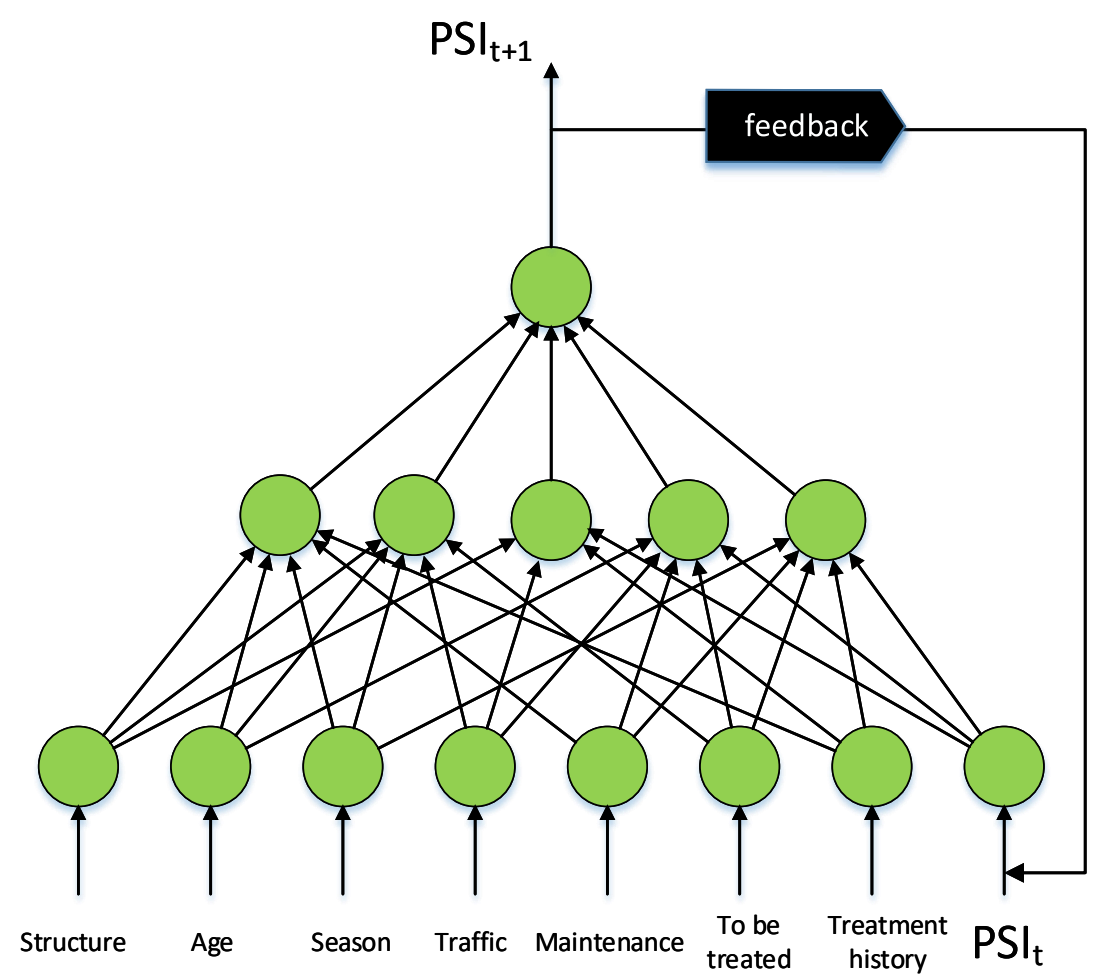

Fig. 11. The RNN used in a two-stage soft computing model for PSI estimation (Tabatabaee et al. 2013).

\section{Condition Rating}

One of the important activities of highway engineers is the determination of pavement condition ratings (PCR), i.e. the assignment of relative weights to various levels of pavement distresses in order to obtain a combined score that indicates the current condition of a roadway section.

According to Pant et al. (1993), no specific guidelines were available for condition evaluation of utility cuts and in the last decade of the last century engineers mostly relied on their experience. Those authors proposed a neural net model to predict utility cut condition index (UCCI) values considering nine types of predominant distresses found at 
Abambres M, Ferreira A (2017). Application of ANN in Pavement Engineering: State-of-Art, hal-02066889

(C) 2017 by Abambres and Ferreira (CC BY 4.0)

utility cuts, namely alligator cracking, edge cracking, transverse cracking, potholes, rutting, raveling and weathering, pavement drop-off, edge separation and corner breaks. Datasets used in ANN modelling include 709 and 323 observations for training and validation, respectively. The neural net employed is a BP-based 30-10-1 MLP, which showed that a larger discrepancy between the predicted and actual outputs existed when the UCCIs were very large or very small, which is believed to have been caused by small sample sizes within these ranges.

Eldin and Senouci (1995a) developed an ANN for pavement condition rating. A BPbased 17-6-1 MLP was used. The number of hidden neurons was selected from 2, 4, 6, 8 and 10, with 6 being the number that yielded the lowest average validation error. Sets of 744 and 1736 examples were prepared for network training and validation, respectively. The results showed that the ANN (i) was able to correctly predict condition ratings even when designed for input data containing high levels of noise, and (ii) outperformed the ODT's prediction model for subjective ratings. Pavement performance (or deterioration) assessment, a key vector of PMS, is usually undertaken through prediction of roughness progression.

Eldin and Senouci (1995b) proposed an ANN based on the condition rating scheme established by Oregon Department of Transportation (ODT). The PCR is computed based on ODT's cracking and rutting indices, including distress type, severity and extent present in the pavement surface. Sets of 744 and 1736 examples were prepared for training and validation purposes, respectively. After a trial-and-error process to find the adequate 
Abambres M, Ferreira A (2017). Application of ANN in Pavement Engineering: State-of-Art, hal-02066889

(C) 2017 by Abambres and Ferreira (CC BY 4.0)

number of hidden neurons $(2,4,6,8$ or 10$)$, a BP-based 22-6-1 MLP network was proposed in this study, which showed good generalization ability.

It is generally difficult to identify what types of variables really influence pavement performance, and for that reason Attoh-Okine (2001) effectively developed a type of ANN called Self-Organizing Map (SOM) for the previous grouping (or clustering) of pavement condition variables (distresses) influencing pavement performance the most. SOM networks are based on (unsupervised) competitive learning (Haykin 2009), which is suitable for classifying a given pattern (or data point) into exactly one of the mutually exclusive classes (the dependent variables of the problem). Pavement condition variables are grouped according to their similarities.

Amin and Amador-Jiménez (2016) applied BP-based 5-3-2-1 MLP networks to predict the pavement condition index (PCI) as function of (i) AADT, Equivalent Single Axle Loads (ESALs), Structural Number (SN), Pavement Age, and the difference in the PCI between the current and last year $(\triangle \mathrm{PCI})$ - flexible pavements, and (ii) AADT, ESALs, Slab Thickness, Pavement Age and $\triangle \mathrm{PCI}$ - rigid pavements. The study categorizes road segments into four categories based on pavement types (e.g., flexible or rigid) and road hierarchies (e.g., arterial or collector), so four ANN models were developed. Although no reference is made to the size of each data set used, it can be assumed that the total amount of data available for this study did not surpass the 6868 examples. As for accuracy, the relative errors obtained in \{ training, validation, testing $\}$ subsets were approximately $\{5,9,9\} \%,\{11,23,72\} \%,\{3,3,4\} \%$ and 
Abambres M, Ferreira A (2017). Application of ANN in Pavement Engineering: State-of-Art, hal-02066889

(C) 2017 by Abambres and Ferreira (CC BY 4.0)

$\{4,4,4\} \%$ for Arterial-Flexible, Arterial-Rigid, Collector-Flexible and Collector-Rigid road segments, respectively.

\subsubsection{Maintenance}

Due to time, budget and other resource constraints, it is not always possible for a highway agency to attend all road sections requiring maintenance within a given period, which calls for a scheme to rank road sections for maintenance treatment according to priority. Traditionally, ranking of highway sections requiring maintenance is based on experience of qualified personnel. Mathematical decision-making criteria have been proposed through the so-called "aggregate condition index", which has shown several drawbacks (Fwa and Chan 1993).

In order to overcome the aforementioned limitations, Fwa and Chan (1993) developed BP-based 6-1-1 MLP neural nets based on 428 (30\% - training, 70\% - validation), 1272 (76\% - training, 24\% - validation), 4396 (93\% - training, 7\% - validation) and 12800 data points (98\% - training, $2 \%$ - validation). It was concluded that all ANNs were able to predict priority ratings within an average absolute error of about 5\%. It was shown that if noise as high as 50\% of the maximum rating score was introduced in the data, the error would rise to about $14 \%$.

Hajek and Hurdal (1993) compared an ANN to an existing knowledge-based expert system called ROSE, designed to determine the need for a specific asphalt concrete (AC) pavement maintenance treatment (routing and sealing). A random training data set of 148 pavement sections was used in this study, whereas validation was carried out by means of a 
Abambres M, Ferreira A (2017). Application of ANN in Pavement Engineering: State-of-Art, hal-02066889

(C) 2017 by Abambres and Ferreira (CC BY 4.0)

random set of 20 instances. The developed ANN is a BP-based 40-x-1 MLP and the obtained results were considered to be reasonably good since the final number of hidden neurons (not disclosed in the paper) was automatically computed by the software used in order to have a maximum tolerance of $10 \%$ when comparing ANN and target outputs.

Flintsch et al. (1996) described an ANN-based simulator to develop and implement an automatic procedure for screening and recommending roadway sections for pavement preservation. A total of 418 examples were available for training (314) and validation (104). After several trials, the BP-based 18-15-1 MLP network was found to be appropriate for selecting candidate sections for a preservation program, since it was able to predict a correct output for $76 \%$ of the validation examples.

Alsugair and Al-Qudrah (1998) developed ANN models to select appropriate maintenance and rehabilitation $(\mathrm{M} \& \mathrm{R})$ action based on pavement condition, which is evaluated as a function of the types of distresses present and their severity levels. Twelve distress types (input variables) and five $M \& R$ actions (output variables) are taken into account (appropriate action was established by experts and/or a pavement management system (PMS) software). The number of examples used in training and validation phases were 9311 and 1862 , respectively. In order to alleviate the closeness of the solution spaces, input data was divided into three groups $(\mathrm{PCI} \leq 70,70<\mathrm{PCI} \leq 85, \mathrm{PCI}>85)$ and one different BP-based MLP ANN was designed for each one. A sensitivity analysis has been conducted varying the number (20 to 36) of hidden nodes in 7 trials, in order to assess the reliability level of each model. In 
Abambres M, Ferreira A (2017). Application of ANN in Pavement Engineering: State-of-Art, hal-02066889

(C) 2017 by Abambres and Ferreira (CC BY 4.0)

general, high levels were obtained and the selected network architectures for each aforementioned PCI range were 12-28-5, 12-22-5 and 12-34-5, respectively.

Abdelrahim and George (2000) evaluated the use of neural nets to predict the optimum maintenance strategy on the basis of realistic (i.e., noisy) data. A set of 144 examples is derived from expert opinions -74 for training and 70 for validation. A genetic adaptive algorithm is employed to train a 10-10-6 MLP network. Six outputs result from the fact that there are six different maintenance strategies to be considered - the selected strategy is coded 1 and the others 0 . The number of hidden units was chosen by trial-and-error. The proposed ANN was able to predict $83 \%$ of the validation examples.

\subsection{Materials and Pavement Design}

\subsubsection{Material Physical Properties}

Saffarzadeh and Heidaripanah (2009) simulated the variation of Marshall Stability (MS) with asphalt content by an LM-based 8-8-1 MLP network. Eighty-five data points were used in training and 25 for cross-validation. The variation of the MS with asphalt content was assessed by a sensitive analysis using the designed ANN and the results were in good agreement with the theory.

Xiao et al. (2011) developed several ANNs to predict the viscosity of various CRM binders at three mixing durations. A LM-based 4-3-1 MLP network was trained with experimental data. Of 216 data points containing three binder sources, 162 were selected for training and the remainder for validation. As can be attested by Fig. 12, the quality of the ANN prediction was quite satisfactory. 
Abambres M, Ferreira A (2017). Application of ANN in Pavement Engineering: State-of-Art, hal-02066889

(C) 2017 by Abambres and Ferreira (CC BY 4.0)

Abo-Hashema (2013) developed an ANN for the prediction of AC layer temperature. Pavement temperature data and some other related parameters have been numerically obtained (690 data points). BP-based 4-25-25-1 MLP model was chosen as the most appropriate after sensitivity analysis, having yielded an average accuracy of $81 \%$ in the validation stage.

Ozturk and Kutay (2014) introduced an ANN model to predict the design properties of superpave asphalt mix, such as percentage of air voids at different gyration levels and the maximum specific gravity. Dataset used comprises 1617 mix designs randomly chosen for training and 200 set aside for validation. The ANN structure was selected after 800 trials, with the LM-based 18-300-300-600-4 MLP net being the most accurate scheme. It was able to produce good results and save at least 3-6 days in the design process.
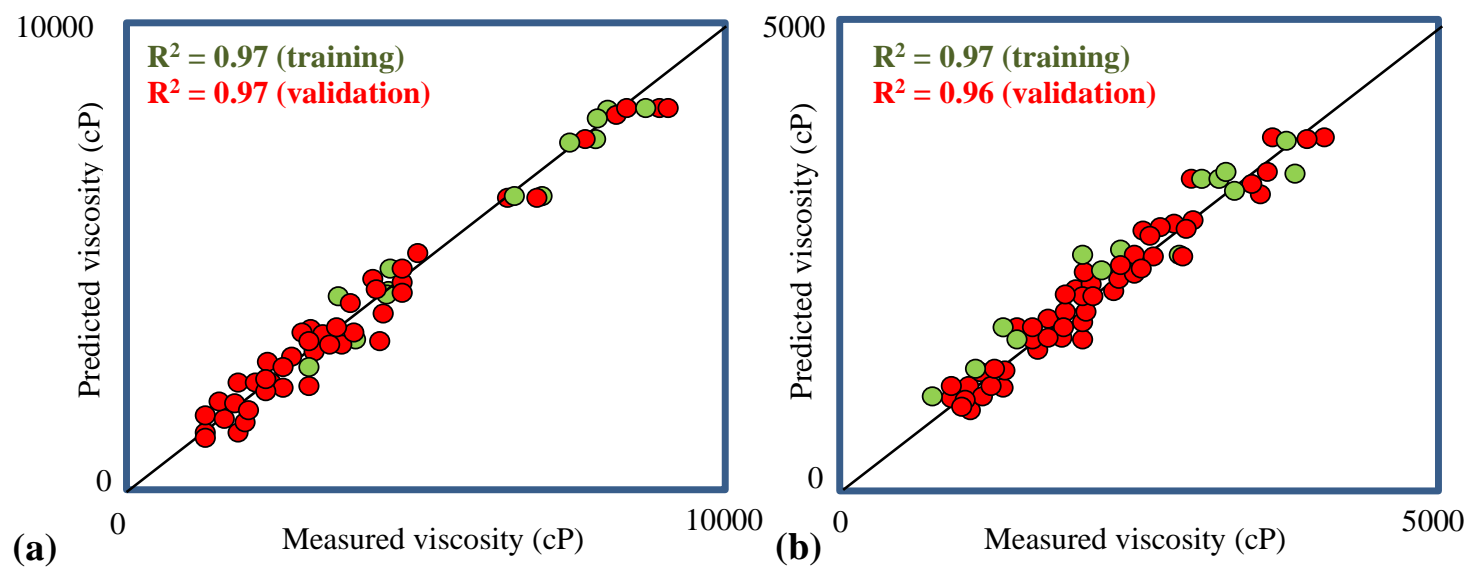

Fig. 12. ANN performances: (a) ambient and (b) cryogenic rubber (based on Xiao et al. 2011).

Specht and Khatchatourian (2014) successfully proposed a LM-based 5-8-6-1 MLP network, trained through 448 examples, to determine the viscosity of asphalt-rubber binders. 
Abambres M, Ferreira A (2017). Application of ANN in Pavement Engineering: State-of-Art, hal-02066889

(C) 2017 by Abambres and Ferreira (CC BY 4.0)

\subsubsection{Layer Moduli / Thickness, Poisson's Ratio}

Backcalculation is an inverse methodology to determine in situ materials stiffness of pavement layer by matching the measured and theoretical deflection with iteration and optimization schemes. One of the drawbacks, besides time, is that minor deviations between measured and computed deflections usually result in significantly different moduli.

Khazanovich And Roesler (1997) implemented an ANN to backcalculate the layer moduli of a three-layer system for a range of pavement layer thicknesses. The necessary data (25000 examples) was obtained by a computer program. Three independent ANN were trained to find (i) modulus of elasticity of the upper constructed layer ( $\left.E_{1}\right)$, (ii) modulus of elasticity of the lower layer $\left(\mathrm{E}_{2}\right)$, and (iii) coefficient of subgrade reaction $(k)$. Whereas (i) the first ANN calculates the pavement deflection profile for a range of pavement layer parameters, in order to reduce the computational time in forward calculations using the aforementioned program, (ii) the second and third ANNs provide $\mathrm{E}_{2} / k$ and $\mathrm{E}_{1} / \mathrm{E}_{2}$ outputs, making use of the estimated $\mathrm{E}_{2} / k$ obtained through the second ANN. All networks were based on an adaptive interpolation methodology with fuzzy subdomains, and they were trained until the relative error was smaller than $1 \%$. Their layout is similar to that of a hierarchical adaptive random partitioning (HARP) network. When an impact is made on a pavement surface of a semi-infinite half-space, surface waves are generated and travel along the surface of the half-space. These surface waves penetrate different depths depending on their wavelengths. 
Abambres M, Ferreira A (2017). Application of ANN in Pavement Engineering: State-of-Art, hal-02066889

(C) 2017 by Abambres and Ferreira (CC BY 4.0)

Kim and Kim (1998) trained several MLP neural nets (learning algorithm not disclosed) to map phase velocities with the corresponding layer moduli (no. of layer moduli are the number of output nodes). Learning data was generated numerically and consisted of 600, 1000 and 2000 data points (training - 50\%, validation - 50\%) for two, three and four-layered pavement systems, respectively. In addition to thickness-related variables (one, two or three variables for two-, three- or four- layered systems, respectively), 19 phase velocity variables were considered as input variables. The MLP network layouts 20-28-2, 21-34-3 and 22-45-4, respectively regarding two-, three- and four-layered pavements, were employed (learning algorithm not disclosed). Very good results were obtained, namely average and maximum errors lower than $2.5 \%$ and $8.7 \%$, respectively.

Ceylan et al. (2007) validated ANN models to predict layer moduli as a function of FWD deflections and layer thicknesses. A total of 24093 runs in a FE program were carried out for data generation (1000 points used for validation and 23094 for training). The BP-based 6-60-60-2 MLP was chosen as the best model for elastic moduli prediction, and the BP-based 12-60-60-1 MLP was adopted to estimate the $K$-parameter from the K$\Theta$ granular base relationship, having yielded an average absolute error of $3.4 \%$.

Sharma and Das (2008) proposed several ANN models to backcalculate layer moduli from normal and noisy deflection basins and layer thicknesses. After trial-and-error of several BP-based MLP topologies (1-2 hidden layers, 7-20 hidden nodes per layer), it was concluded that one hidden layer and 10-15 neurons yields the best results. A total of 6000 sets of deflection basin data are used, 5800 of those employed in network training. The 
Abambres M, Ferreira A (2017). Application of ANN in Pavement Engineering: State-of-Art, hal-02066889

(C) 2017 by Abambres and Ferreira (CC BY 4.0)

performance of the ANN was found to be satisfactory in terms of (i) computation time and (ii) accuracy.

Gopalakrishnan (2008) developed an ANN to backcalculate airport flexible pavement moduli based on heavy weight deflectometer (HWD) test data. Three thousand, seven hundred and fifty data vectors were used in training and 1250 in validation. Separate ANN models were used for each output variable and parametric analysis was carried out to select the best architectures. Concerning AC and subgrade moduli prediction, the BP-based 6-40-40-1 (average absolute error in validation $=8.2 \%)$ and 8-40-40-1 (average absolute error in validation $=7.6 \%)$ MLP nets produced the best results, respectively.

Gopalakrishnan and Ceylan (2008) employed ANN-based structural models to accurately predict flexible airport pavement layer moduli from realistic FWD deflection basins. Data for ANN learning was numerically obtained, with 23093 points for training and 1000 for validation. Two separate models were proposed for the prediction of AC and subgrade Young modulus, as a function of six pavement surface deflections and two layer thicknesses ( 8 input variables). The developed BP-based 8-60-60-1 MLP models exhibited average absolute errors smaller than $1.5 \%$ for the validation subset, as shown in Fig. 13 .

Bayrak and Ceylan (2008) proposed two ANNs to backcalculate rigid pavement parameters using FWD data. To train those models, 39026 and 49539 FEA-based samples were used in the training of elastic modulus and coefficient of subgrade reaction, respectively, whereas 2000 different examples were taken for validation of each ANN. The designed 
Abambres M, Ferreira A (2017). Application of ANN in Pavement Engineering: State-of-Art, hal-02066889

(C) 2017 by Abambres and Ferreira (CC BY 4.0)

models were BP-based 8-60-60-1 and 7-60-60-1 MLP nets, respectively, both associated with average absolute errors smaller than $0.3 \%$.

Park et al. (2009) proposed several neural networks to predict RM of subgrade and subbase pavement materials from several basic soil properties. For subgrade soils, 236 and 36 data points were employed for training and validation, respectively, with 164 and 26 being the size of the subbase soil-related subsets. The best performing ANN schemes were the BP-based 6-4-1 (subgrade) and 3-5-1 (subbase) MLPs, which yielded great results (e.g., $\mathrm{R} \geq 0.975$ for the best subbase material model).

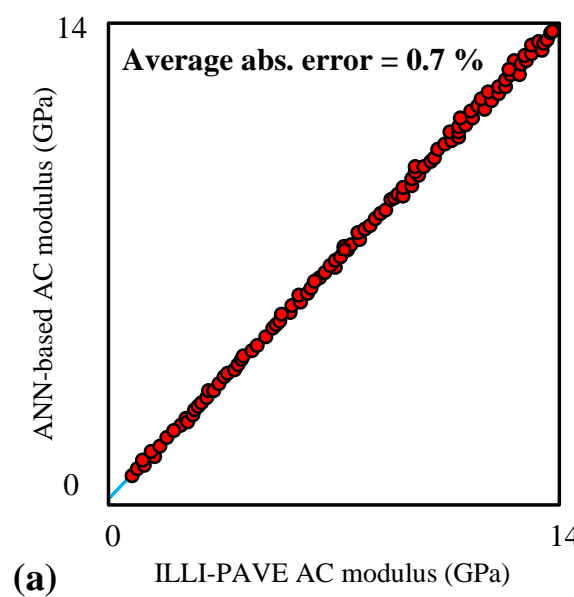

(a)

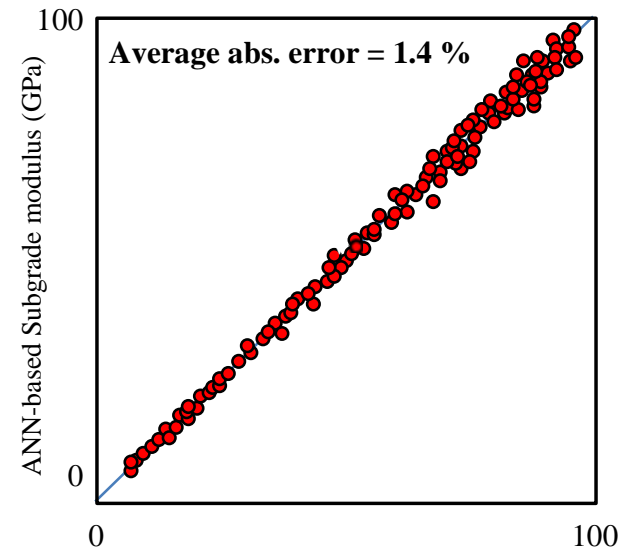

(b) ILLI-PAVE Subgrade modulus (GPa)

Fig. 13. FEA vs ANN validation results: (a) AC, (b) Subgrade (based on Gopalakrishnan \& Ceylan 2008).

Abdallah and Nazarian (2009) proposed five ANNs to estimate the moduli of three pavement layers and the thickness of AC and base layers, namely BP-based MLPs with the following layouts: 10-28-1, 13-25-1, 14-28-1, 15-30-1, 19-14-1. The validation results (250 
Abambres M, Ferreira A (2017). Application of ANN in Pavement Engineering: State-of-Art, hal-02066889

(C) 2017 by Abambres and Ferreira (CC BY 4.0)

data points) showed that, for all models except the base thickness, at least $90 \%$ of the results had a relative error equal or smaller than $20 \%$, which is quite satisfactory.

Xiao and Amirkhanian (2009) proposed four neural nets to estimate the stiffness behavior of modified asphalt mixtures at $5^{\circ} \mathrm{C}$ and $20^{\circ} \mathrm{C}$. BP-based 5-3-1 and 5-6-1 MLP networks were designed. In the learning stage, each temperature included 64 and 84 (63 for training and 21 for validation) sample datasets for the specimens containing cryogenic and ambient rubbers, respectively. Obtained results for ambient rubberized mixes were quite accurate for the training set $\left(\mathrm{R}^{2} \geq 0.95\right)$ but not so for the validation $\left(\mathrm{R}^{2}=0.57\right.$ at $5^{\circ} \mathrm{C}$ and $\mathrm{R}^{2}=0.71$ at $\left.20^{\circ} \mathrm{C}\right)$

Solanki et al. (2009) compared two ANN models (RBF and MLP nets), to correlate RM with routine properties of subgrade soils and state of stress. Ninety-eight examples were used, 64 in training and 34 in validation. The 7-6-6-1 MLP model (learning algorithm not disclosed) exhibited the best performance and predicted RM for pavement design with reasonable accuracy.

Zaman et al. (2010) developed several types of ANN models to correlate RM with routine properties of subgrade soils and state of stress. RBF, MLP and Generalized Regression (GRNN) neural networks are performing best, characterized by the following layouts: 7-1250-2-1 (GRNN), 7-100-1 (RBFNN), 7-6-6-1 (MLP) (learning algorithms not disclosed). Ninety-eight soils made up the total data available, from which 64 were used for training and 34 for validation. The MLP model proved to be best when considering the whole dataset. 
Abambres M, Ferreira A (2017). Application of ANN in Pavement Engineering: State-of-Art, hal-02066889

(C) 2017 by Abambres and Ferreira (CC BY 4.0)

Kim et al. (2010) assessed the influence of using different input normalization methods in the prediction of pavement layer moduli using an ANN. Five normalization schemes were tested and it was concluded that the results were highly dependent on the selected technique. Six thousand and four hundred data samples were used in training and a different subset of the same amount was used for validation. A BP-based 16-38-1 MLP network was used in this research, and the best normalization method for the $p^{\text {th }}$ example of variable $u$ reads

$$
\bar{x}_{p}^{u}= \begin{cases}\frac{x_{p, \text { max }}^{u}-x_{p}^{u}}{x_{p, \text { max }}^{u}-x_{p, \text { min }}^{u}}, & x_{p, \text { max }}^{u}>0 \\ x_{p}^{u} & , x_{p, \text { max }}^{u} \leq 0\end{cases}
$$

where $x_{p, \max }^{u}$ and $x_{p, \min }^{u}$ are the maximum and minimum values among all variable values for all samples used in training.

Kok et al. (2010) implemented an ANN to estimate the complex modulus of StyreneButadiene-Styrene polymer modified bitumen. LM-based 3-2-1 MLP network yielded highly accurate results after testing several numbers of hidden nodes. The database used was made of 192 samples, which were used in a five-fold cross-validation scheme, i.e. the data is randomly split into five exclusive subsets of approximately equal size, and at each time one of them is used for validation and the other four put together to form a training subset.

Nazzal and Tatari (2013) used GA and BP-based ANNs to predict subgrade RM based on soil index properties. RM test results were collected to construct a databank. MLP and 
Abambres M, Ferreira A (2017). Application of ANN in Pavement Engineering: State-of-Art, hal-02066889

(C) 2017 by Abambres and Ferreira (CC BY 4.0)

RBF nets with different numbers of hidden nodes were tested, and the selected models for the prediction of several coefficients were: 5-4-1 MLP $\left(\mathrm{k}_{1}\right)$, 4-7-1 MLP $\left(\mathrm{k}_{2}\right), 5-8-1$ MLP $\left(\mathrm{k}_{3}\right)$. GA were then used to analyze whether better prediction models could be devised by selecting the ANN input variables, resulting in the following optimal models: 10-10-1 MLP ( $\left.\mathrm{k}_{1}\right), 9-9-1$ MLP $\left(\mathrm{k}_{2}\right)$, 7-6-1 MLP $\left(\mathrm{k}_{3}\right)$, which outperformed the former ones and yielded great validation results $\left(\mathrm{R}^{2}>0.92\right)$. However, it should be borne in mind that the models that did not use GA did not employ any technique for input variable selection, which means it is not a fair comparison with the GA-based counterpart.

Singh et al. (2013) developed an ANN that integrates aggregate shape parameters in the estimation of dynamic modulus. A total of 1440 dynamic moduli measured values were used in learning - 1152 data points were used for training and 288 for validation. A LM-based 8-20-20-1 MLP network was designed after hidden node-based sensitivity analysis. It was shown that the inclusion of aggregate shapes enhanced the prediction capability of the model, which exhibited a mean absolute relative error of $10.2 \%$ and $17.5 \%$ for the training and validation subsets, respectively.

Saltan et al. (2013) developed an ANN-based backcalculation procedure where the data used were obtained through 114 FEA, including surface deflections for long-term pavement performance (input variables) and AC elastic modulus and Poisson's ratio. In this data, 95 data points were used for training and the remainder for validation. The final design was obtained with a LM-based 7-15-3 MLP network, which yielded a mean absolute relative error less than $3.5 \%$ for any subset. 
Abambres M, Ferreira A (2017). Application of ANN in Pavement Engineering: State-of-Art, hal-02066889

(C) 2017 by Abambres and Ferreira (CC BY 4.0)

By means of an ANN model, Tarawneh and Nazzal (2014) improved the RM prediction from falling weight deflectometer (FWD) results. After sensitivity analysis, LM-based 10-4-1 MLP network yielded the smallest error and one of the highest $\mathrm{R}^{2}$ (amount of learning data not disclosed).

Kim et al. (2014) developed an ANN to predict subgrade RM using physical properties and stress state. The training and validation subsets contain 195 and 75 observations, respectively. The chosen network is a BP-based 15-9-1 MLP, and there is a fairly good alignment between the ANN-estimated and the lab-measured RM.

Pożarycki (2015) developed an ANN to predict bituminous layer thickness, where 147, 31 and 31 data point subsets were employed in training, validation and testing, respectively. The Broyden-Fletcher-Goldfarb-Shanno-based (learning algorithm) 5-9-1 MLP network was proposed, with the inputs being (i) FWD deflection data in 3 points, (ii) temperature and (iii) applied stress. Validation mean absolute percentage error was inferior to $14 \%$.

Leiva-Villacorta et al. (2016) developed ANN models capable of reliably predicting pavement layer moduli. A database was generated using layered-elastic analysis for a three-layered flexible pavement structure. For each ANN, a total of 100000 data points were generated. A BP-based 13-20-20-3 MLP network was found to be the most appropriate and proved to yield highly correlated estimations $\left(\mathrm{R}^{2} \geq 0.99\right)$. 
Abambres M, Ferreira A (2017). Application of ANN in Pavement Engineering: State-of-Art, hal-02066889

(C) 2017 by Abambres and Ferreira (CC BY 4.0)

\subsubsection{Stress, Strain, Deflections and Creep}

Attoh-Okine and Fekpe (1997) examined the use of generalized adaptive ANN for modeling field strength characteristics of lateritic soils. In these types of networks, there is no a priori specification of the architecture - it grows to fit the problem at hand. A total of 45 observation data were used, 25 for training and 20 for validation. A BP-based 7-52-1 MLP network was developed for comparison purposes $\left(\mathrm{R}^{2}=0.580\right)$. The designed adaptive ANN is a 5-3-2-1 partially connected MLP based on an evolutionary learning algorithm $\left(\mathrm{R}^{2}=0.735\right)$.

Meier et al. (1997) implemented an ANN where the goal was to compute forwardproblem solutions, i.e. surface deflections as a function of layer moduli. Ten thousand examples were used in learning for each network. Various architectures were investigated and four BP-based 5-15-15-10 MLP networks were successfully proposed.

Ceylan et al. (1999) developed an ANN based on 38000 FEA results (35280 for training) for the prediction of stresses and deflections in jointed concrete airfield pavements. A BP-based 6-29-29-3 MLP network was selected as optimal after sensitivity analysis among 21 two-hidden layered different topologies. The average error associated to ANN results was smaller than $0.5 \%$.

Ceylan et al. (2005) developed ANN-based structural models to accurately predict pavement critical stresses/strains and layer moduli based on realistic FWD deflection profiles. A total of 2000 FEA results were employed in learning (1800 for training) for each network. Two ANN were developed, namely a BP-based MLP with layouts 5-6060-2 (A) and 5-60-60-3 (B). Four surface deflections and AC layer thickness are the 
Abambres M, Ferreira A (2017). Application of ANN in Pavement Engineering: State-of-Art, hal-02066889

(C) 2017 by Abambres and Ferreira (CC BY 4.0)

inputs; layer moduli and critical stress/strains the outputs in models A and B, respectively. In model $\mathrm{A}$, the maximum absolute average error for deflection data with $20 \%$ of noise level was $5.2 \%$. For model B without noise, the maximum error was $1.1 \%$.

Zofka and Yut (2012) analysed the feasibility of using three ANNs for the prediction of hot mix asphalt creep compliance from the binder creep compliance and vice-versa. Each network dataset $(600,594$ and 594 points each) was randomly divided into training $(60 \%)$, validation $(20 \%)$ and testing (20\%) subsets. The proposed networks were BPbased 11-20-6, 15-20-6 and 12-20-6 MLPs. The ANN models demonstrated very high correlation (97-99\%) when their results were compared to the target counterpart.

Tapkin et al. (2012) developed ANNs to predict (i) strain accumulation and creep stiffness and (ii) stability, flow and Marshall Quotient of AC specimens, from a series of Marshall designs based on experimental results (number of data samples not disclosed). Optimal networks were found to be (i) LM-based 7-9-1 and 6-8-1 MLPs (strain and creep), and (ii) LM-based 6-8-1 (stability), 6-3-1 (flow), 6-10-1 (Marshall Quotient) MLPs. Obtained results are very close to actual test results.

Ghanizadeh and Fakhri (2014) proposed an ANN model to predict the effective length of longitudinal and transverse stress and strain pulses at the bottom of the asphalt layer. In order to obtain data for this study, 5000 flexible pavement sections were analyzed using layered elastic theory (3000 in training, 500 for cross-validation and 1500 for testing). The LM-based 7-15-4 MLP network has proven to be a highly accurate model $\left(\mathrm{R}^{2}=0.999\right)$. 
Abambres M, Ferreira A (2017). Application of ANN in Pavement Engineering: State-of-Art, hal-02066889

(C) 2017 by Abambres and Ferreira (CC BY 4.0)

Ceyan et al. (2014) developed a hybrid evolutionary global optimization algorithm (shuffled complex evolution - SCE) integrated with an ANN model, where the latter serves as a surrogate forward model to map pavement layer moduli to surface deflections for a variety of scenarios. Data (41106 points, 150 of those used for validation) was simulated using FEA. The LM-based 3-60-60-6 MLP network was used, and the hybrid model ANN-SCE yielded virtually perfect results (average error smaller than 1\%).

Raab et al. (2015) applied three ANNs for the analysis of interlayer bonding properties change over time. The datasets used come from different research projects and laboratory studies - 182 samples for lab A (25 for validation), 140 samples for lab B (20 for validation), and 138 samples for lab C (22 for validation). The output variables considered are the maximum shear force and maximum nominal shear stress. The three neural nets obtained for each dataset were BP-based MLP with the following structures: (i) 4-3-2 (lab A) and (ii) 6-3-2 (labs B and C). The results obtained were similar to the ones yielded by conventional techniques.

Saleh (2015) developed an ANN to predict stresses and deflections in rigid pavements. Different loading combinations, layer moduli and pavement composition were modeled by finite elements (1037 analysis results used in training, 259 in validation/testing). The network 8-12-7-6 MLP (learning algorithm not disclosed) was designed and proved to be very accurate, except for shear stress prediction.

Shafabakhsh et al. (2015) developed ANNs for the prediction of longitudinal strains at the bottom of the asphalt layer of flexible pavements subjected to moving loads. Data is obtained 
Abambres M, Ferreira A (2017). Application of ANN in Pavement Engineering: State-of-Art, hal-02066889

(C) 2017 by Abambres and Ferreira (CC BY 4.0)

using 350 advanced FEA (334 used for training). After sensitivity analysis regarding the number of hidden nodes, the LM-based 7-13-1 MLP network was deemed to be the best alternative for this problem. It was found that the correlation between prediction and target values is very high for all datasets (e.g., $R^{2}>0.99$ ).

Plati et al. (2016) developed an ANN model for the prediction of strains based on in situ gathered data -240 pavement sections were considered for training, and another 240 for validation/testing. The built network is a Quasi-Newton-based 5-4-1 MLP. The neural net investigated proved to be an effective tool to assist decision makers in PMS, as shown in Fig. 14.

\subsubsection{Equivalent Single Axle Load (ESAL)}

AASHTO (American Association of State Highway and Transportation Officials) design equation has been used in pavement thickness design to calculate the structural number, i.e., the required pavement strength.

Tigdemir (2014) developed two BP-based 7-20-1 MLP neural networks (same input variables) aiming at predicting (i) AASHTO-based design life and (ii) the relation between the AASHTO-based (computed by the first model) and the real design life of pavements, in terms of ESAL. From a total of 234 sections, the training dataset is comprised of 164 random sections, while the remainder is equally split for validation and testing purposes. The first model produced excellent results $\left(\mathrm{R}^{2}=0.999\right)$, whereas the second model yielded acceptable results only for the training and testing datasets $\left(\mathrm{R}^{2}>0.90\right)$ - significant errors were found for the validation counterpart. Lastly, Tigdemir (2014) proposed a BP-based 7-20-2 MLP net 
Abambres M, Ferreira A (2017). Application of ANN in Pavement Engineering: State-of-Art, hal-02066889

(C) 2017 by Abambres and Ferreira (CC BY 4.0)

that integrates both outputs mentioned before and keeps the same input variables. Good correlations were obtained for each output variable, namely $R^{2}=\{0.97,0.94\}$.

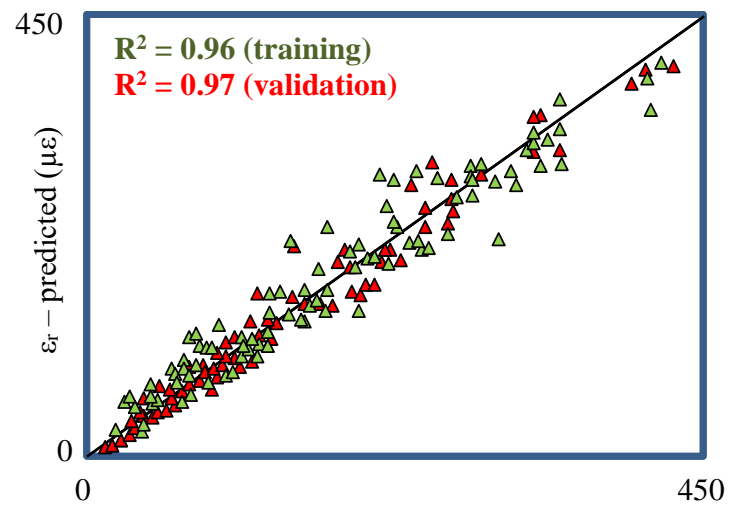

(a)

$\varepsilon_{\mathrm{r}}-$ calculated $(\mu \varepsilon)$

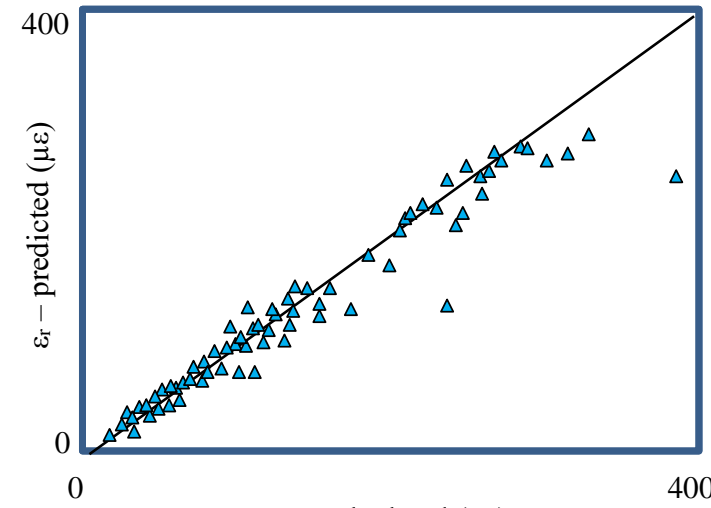

(b)

Fig. 14. (a) Training, validation and (b) testing ANN predictions (based on Plati et al. 2016).

\subsection{Frequency of application of each ANN feature}

In this final sub-section, Tabs. 1-4 summarize the main ANN design features employed per pavement engineering problem addressed in this paper, so that the reader can decide much quicker which features to include in a neural net-based parametric analysis of similar problems. Moreover, histograms covering three important pavement engineering fields (first column of Tabs. 1-4) are presented in Figs. 15-17 to give a graphical insight of the frequency of use of each ANN feature in the final design. It is possible to conclude that: 


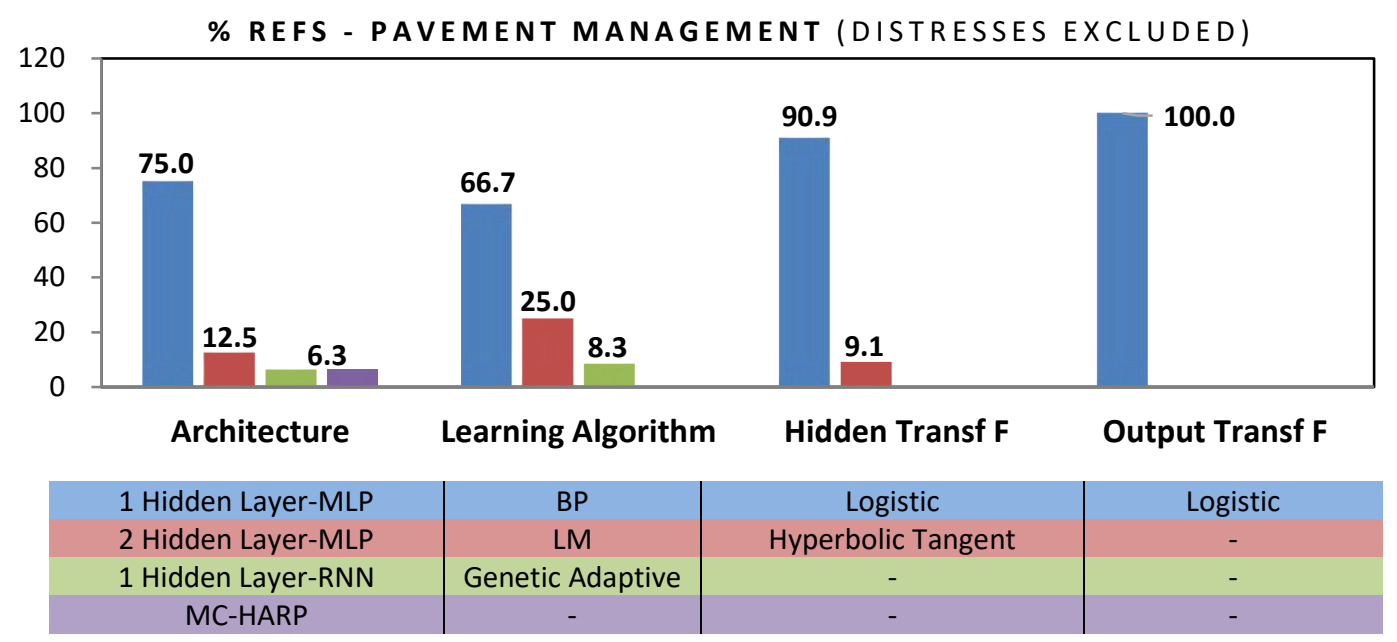

Fig. 15. Frequency of ANN features in pavement management problems (distresses not covered - Tab. 1)

(i) The one hidden layer-MLP has been the most used neural net architecture by far in both pavement management (except distresses) $(75.0 \%)$ and pavement materials \& design $(60.7 \%)$ problems, while it comes in second behind the two hidden layer-MLP (44.4\%) for pavement distress studies.

(ii) The error backpropagation has been the most employed learning algorithm in any of the three pavement engineering fields addressed, having been used in more than $55 \%$ of the works. (iii) The logistic hidden node transfer function is by far $(90.9 \%)$ the "winner" in pavement management problems. In the other two fields, it also takes the lead but by less than an eleven percent point difference over the hyperbolic tangent function. 
Abambres M, Ferreira A (2017). Application of ANN in Pavement Engineering: State-of-Art, hal-02066889

(C) 2017 by Abambres and Ferreira (CC BY 4.0)

Table 1. ANN features employed in pavement management problems (distresses not covered).

\begin{tabular}{|c|c|c|c|c|c|c|c|}
\hline \multirow[b]{2}{*}{ Field } & \multirow[b]{2}{*}{ Problem } & \multicolumn{4}{|c|}{ ANN Feature } & \multirow[b]{2}{*}{ Quality } & \multirow[b]{2}{*}{ Ref } \\
\hline & & Architecture & $\begin{array}{l}\text { Learn. } \\
\text { Algorit. }\end{array}$ & $\begin{array}{l}\text { Hid./ Out. } \\
\text { Transfer } \\
\text { Functions }\end{array}$ & $10^{\frac{\log (\mathrm{LD})}{I V}}$ & & \\
\hline \multirow{14}{*}{$\begin{array}{l}\text { Pavement } \\
\text { Manag. }\end{array}$} & \multirow[b]{2}{*}{$\begin{array}{c}\text { Skid } \\
\text { Resistance }\end{array}$} & PC 4-3-2-1 MLP & - & - & 3 & $\begin{array}{l}\text { Good } \\
\text { (G) }\end{array}$ & $\begin{array}{c}\text { Owusu-Ababio } \\
1995 \\
\end{array}$ \\
\hline & & 2-3-1 MLP & LM & - & 27 & $\begin{array}{l}\text { Very } \\
\text { Good } \\
\text { (VG) }\end{array}$ & $\begin{array}{l}\text { Bosurgi \& } \\
\text { Trifirò } 2005\end{array}$ \\
\hline & \multirow{5}{*}{ Maintenance } & 6-1-1 MLP & $\mathrm{BP}$ & Logistic & 5 & VG & $\begin{array}{c}\text { Fwa \& } \\
\text { Chan } 1993\end{array}$ \\
\hline & & 40-x-1 MLP & $\mathrm{BP}$ & Logistic & 1 & $\mathrm{G}$ & $\begin{array}{c}\text { Hajek \& } \\
\text { Hurdal } 1993 \\
\end{array}$ \\
\hline & & 18-15-1 MLP & BP & Logistic & 1 & G & $\begin{array}{c}\text { Flintsch et al. } \\
1996\end{array}$ \\
\hline & & $\begin{array}{l}12-22-5 \text { MLP } \\
12-28-5 \text { MLP } \\
12-34-5 \text { MLP }\end{array}$ & $\mathrm{BP}$ & Logistic & 1 & VG & $\begin{array}{l}\text { Alsugair \& Al- } \\
\text { Qudrah } 1998\end{array}$ \\
\hline & & 10-10-6 MLP & $\begin{array}{l}\text { Genetic } \\
\text { Adapt. }\end{array}$ & Logistic & 2 & G & $\begin{array}{l}\text { Abdelrahim \& } \\
\text { George } 2000\end{array}$ \\
\hline & \multirow{4}{*}{$\begin{array}{l}\text { Condition } \\
\text { Rating }\end{array}$} & 30-10-1 MLP & $\mathrm{BP}$ & Logistic & 1 & $\mathrm{NG}$ & Pant et al. 1993 \\
\hline & & 22-6-1 MLP & $\mathrm{BP}$ & Logistic & 1 & $G$ & $\begin{array}{c}\text { Eldin \& } \\
\text { Senouci 1995b }\end{array}$ \\
\hline & & 17-6-1 MLP & BP & Logistic & 1 & G & $\begin{array}{c}\text { Eldin \& } \\
\text { Senouci } \\
1995 a \\
\end{array}$ \\
\hline & & 5-3-2-1 MLP & $\mathrm{BP}$ & Logistic & - & VG & $\begin{array}{c}\text { Amin \& } \\
\text { Amador- } \\
\text { Jiménez } 2016\end{array}$ \\
\hline & \multirow{3}{*}{$\begin{array}{c}\text { Present } \\
\text { Serviceability } \\
\text { Index (PSI) / } \\
\text { Ratio (PSR) }\end{array}$} & $\begin{array}{c}\text { Monte Carlo } \\
\text { HARP }\end{array}$ & - & - & 7 & G & $\begin{array}{c}\text { Banan \& } \\
\text { Hjelmstad } 1996\end{array}$ \\
\hline & & 5-4-1 MLP & LM & Logistic & 2 & $\mathrm{G}$ & Terzi 2007 \\
\hline & & 8-5-1 RNN & LM & Нyp. Tg / - & - & VG & $\begin{array}{c}\text { Tabatabaee et } \\
\text { al. } 2013\end{array}$ \\
\hline
\end{tabular}

(iv) For the output neurons, the logistic transfer function predominates in all fields except pavement distresses, where the linear function was employed in $63.6 \%$ of the cases.

(v) Fig. 18 presents the distribution of the "ANN feature" in the fourth column of Tabs. 1-4 for all the references analyzed. That value represents the round of the constant amount of values (a) per input variable that needed to be considered if LD (total amount of learning data points) equaled the total number of input data combinations - "a" from $\mathrm{a}^{\mathrm{IV}}=\mathrm{LD}$ was computed and then rounded to the closest integer, where IV is the number of input variables. 
Abambres M, Ferreira A (2017). Application of ANN in Pavement Engineering: State-of-Art, hal-02066889

(C) 2017 by Abambres and Ferreira (CC BY 4.0)

Table 2. ANN features employed in pavement distress problems.

\begin{tabular}{|c|c|c|c|c|c|c|c|}
\hline \multirow[b]{2}{*}{ Field } & \multirow[b]{2}{*}{ Problem } & \multicolumn{4}{|c|}{ ANN Feature } & \multirow[b]{2}{*}{ Quality } & \multirow[b]{2}{*}{ Ref } \\
\hline & & Architecture & $\begin{array}{l}\text { Learning } \\
\text { Algorithm }\end{array}$ & $\begin{array}{l}\text { Hid./Out. } \\
\text { Transfer } \\
\text { Function }\end{array}$ & $10^{\frac{\log (\mathrm{LD})}{I V}}$ & & \\
\hline \multirow{17}{*}{$\begin{array}{l}\text { Pavement } \\
\text { Distresses }\end{array}$} & $\begin{array}{c}\text { Joint } \\
\text { Faulting } \\
\end{array}$ & 8-8-8-1 MLP & BP & - & 2 & $\mathrm{G}$ & $\begin{array}{c}\text { Saghafi et al. } \\
2009\end{array}$ \\
\hline & \multirow{7}{*}{ Roughness } & $\begin{array}{l}\text { PC 4-5-4-2-1 } \\
\text { Generalized } \\
\text { Adaptive ANN }\end{array}$ & $\begin{array}{c}\text { Self- } \\
\text { Organized }\end{array}$ & Linear & 2 & $\mathrm{G}$ & $\begin{array}{c}\text { Roberts \& } \\
\text { Attoh-Ok } 98\end{array}$ \\
\hline & & 1-20-3 RBFNN & BP & $\begin{array}{l}\text { Gaussian } \\
\text { / Linear }\end{array}$ & 80000 & $\mathrm{G}$ & $\begin{array}{c}\text { Yildirim \& } \\
\text { Uz. } 01\end{array}$ \\
\hline & & 6-10-1 MLP & BP & Logistic & 2 & $\mathrm{G}$ & $\begin{array}{c}\text { Choi et al. } \\
2004\end{array}$ \\
\hline & & $x-6-6-4$ RNN & LM & $\begin{array}{l}\text { Hyp. Tg / } \\
\text { Linear }\end{array}$ & - & $\mathrm{G}$ & $\begin{array}{c}\text { Yousefzadeh } \\
\text { et al. } \\
2010 \\
\end{array}$ \\
\hline & & $x-15-4$ WNN & BP & $\begin{array}{l}\text { Mexican } \\
\text { Hat } \\
\text { Wavelet / } \\
\text { Linear }\end{array}$ & - & VG & $\begin{array}{l}\text { Solhmirzaei } \\
\text { et al. } 2012\end{array}$ \\
\hline & & 3-50-50-2 MLP & LM & $\begin{array}{l}\text { Hyp. Tg / } \\
\text { Linear }\end{array}$ & 16 & VG & $\begin{array}{c}\text { Ngwangwa } \\
\text { et al } 14\end{array}$ \\
\hline & & $\begin{array}{c}\text { 9-80-50-30-1 } \\
\text { MLP } \\
\text { 9-3-1 MLP } \\
\text { 9-8-1 MLP }\end{array}$ & LM & $\begin{array}{l}\text { Hyp. Tg / } \\
\text { Linear }\end{array}$ & 2 & VG & $\begin{array}{l}\text { Ziari et al } \\
2016\end{array}$ \\
\hline & \multirow{9}{*}{ Cracking } & 5-5-5 MLP & $\mathrm{BP}$ & - & - & VG & Kaseko 1993 \\
\hline & & 3-5-1 MLP & BP & Logistic & 4 & $\mathrm{G}$ & $\begin{array}{c}\text { Owusu- } \\
\text { Ababio } 98\end{array}$ \\
\hline & & 8-10-8-1 MLP & LM & - & 2 & $\mathrm{G}$ & $\begin{array}{c}\text { Mei et al. } \\
2004\end{array}$ \\
\hline & & 3-150-3 MLP & $\mathrm{BP}$ & - & 8 & VG & Lee 2004 \\
\hline & & $\begin{array}{l}\text { 8-40-40-1 MLP } \\
\text { 9-40-40-1 MLP } \\
\text { 7-40-40-1 MLP } \\
\text { 9-40-40-1 MLP }\end{array}$ & BP & Logistic & $\begin{array}{l}3 \\
2 \\
3 \\
2\end{array}$ & VG & $\begin{array}{c}\text { Ceylan et al. } \\
2011\end{array}$ \\
\hline & & $\begin{array}{c}\text { 26-7-7-7-1 MLP } \\
\text { 26-5-5-1 MLP } \\
\text { 29-7-7-7-1 MLP } \\
\text { 31-6-6-1 MLP }\end{array}$ & BP & Нур. Tg / - & $\begin{array}{l}1 \\
1 \\
1 \\
-\end{array}$ & VG & Thube 12 \\
\hline & & $\begin{array}{l}\text { 7-60-60-1 MLP } \\
9-60-60-1 \text { MLP }\end{array}$ & LM & $\begin{array}{l}\text { Logistic / } \\
\text { Linear }\end{array}$ & $\begin{array}{l}4 \\
3 \\
\end{array}$ & $\mathrm{G}$ & $\begin{array}{c}\text { Wu et al. } \\
2014\end{array}$ \\
\hline & & $\begin{array}{c}\text { 4-7-2 MLP } \\
\text { 4-5-2 RBFNN }\end{array}$ & BP & - & - & $\begin{array}{l}\text { VG } \\
\text { NG }\end{array}$ & $\begin{array}{c}\text { Gajewski } \\
\text { Sadowski } \\
2014\end{array}$ \\
\hline & & 8-12-8-2 MLP & $\mathrm{BP}$ & Logistic & 3 & VG & $\begin{array}{c}\text { Yoo \& Kim } \\
2016\end{array}$ \\
\hline
\end{tabular}


Abambres M, Ferreira A (2017). Application of ANN in Pavement Engineering: State-of-Art, hal-02066889

(C) 2017 by Abambres and Ferreira (CC BY 4.0)

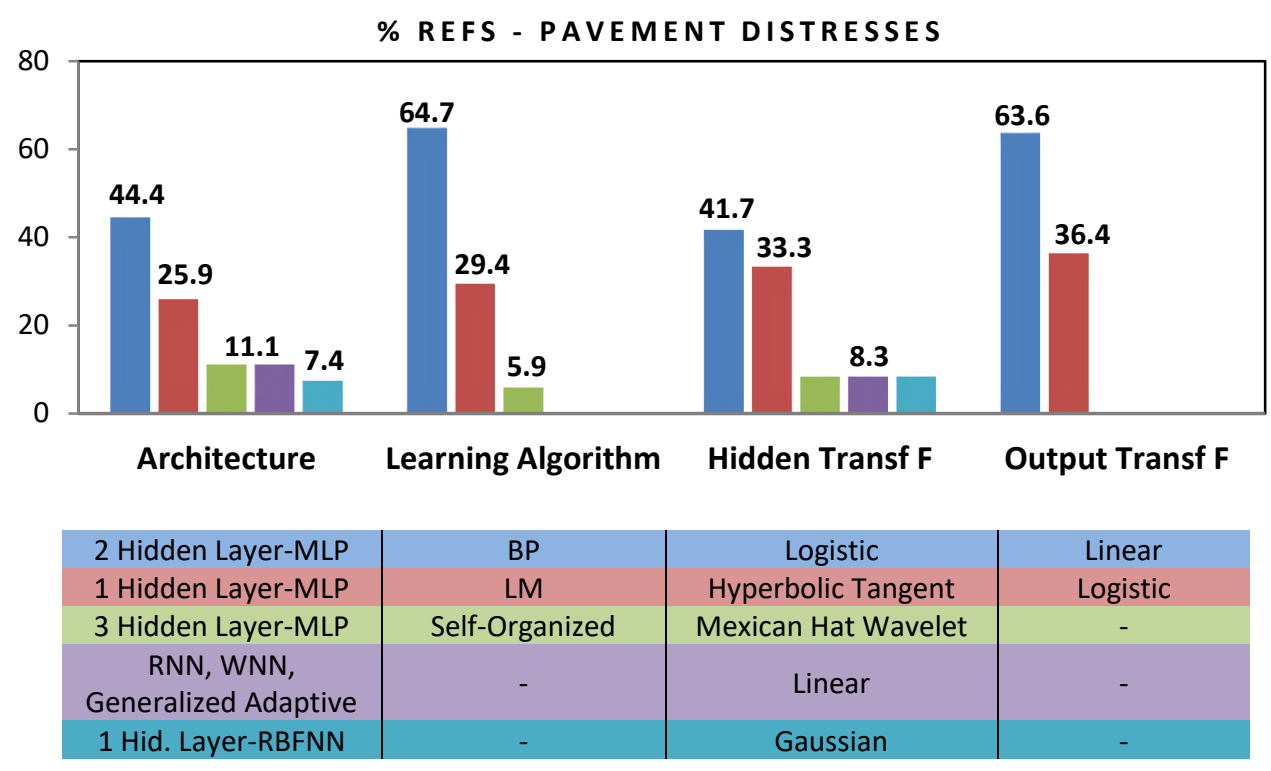

Fig. 16. Frequency of ANN features in pavement distress problems (Tab. 2).

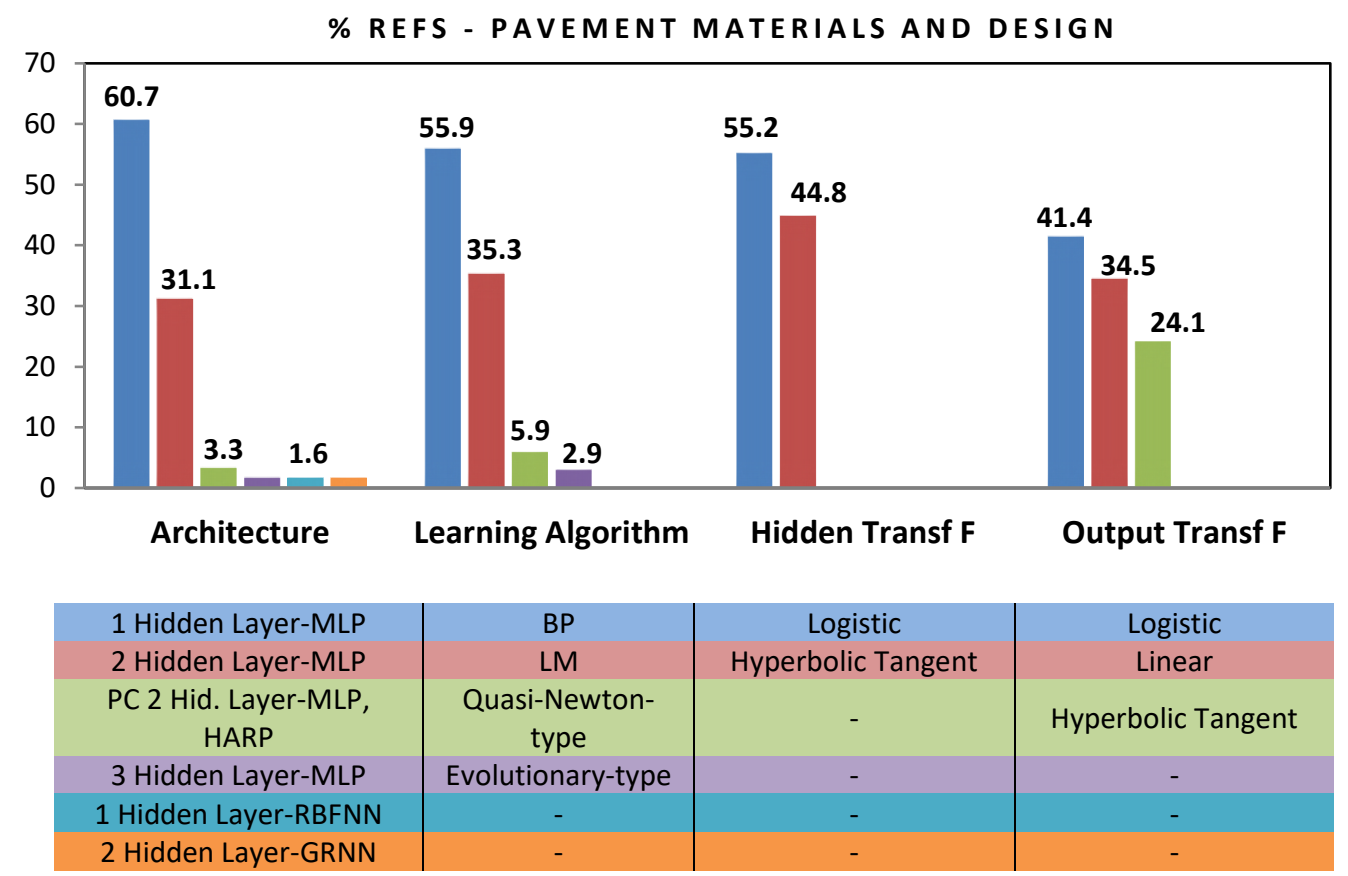

Fig. 17. Frequency of ANN features in pavement materials and design problems (Tabs. 3-4). 
Abambres M, Ferreira A (2017). Application of ANN in Pavement Engineering: State-of-Art, hal-02066889

(C) 2017 by Abambres and Ferreira (CC BY 4.0)

Table 3. ANN features employed in pavement materials and design problems: layer moduli / thickness and Poisson's ratio.

\begin{tabular}{|c|c|c|c|c|c|c|c|}
\hline \multirow[b]{2}{*}{ Field } & \multirow[b]{2}{*}{ Problem } & \multicolumn{4}{|c|}{ ANN Feature } & \multirow[b]{2}{*}{ Quality } & \multirow[b]{2}{*}{ Ref } \\
\hline & & Architecture & $\begin{array}{l}\text { Learn. } \\
\text { Alg. }\end{array}$ & $\begin{array}{l}\text { Hid./Out. } \\
\text { Transfer } \\
\text { Function }\end{array}$ & $10^{\frac{\log (\mathrm{LD})}{I V}}$ & & \\
\hline \multirow{21}{*}{$\begin{array}{l}\text { Materials } \\
\text { and Pav. } \\
\text { Design }\end{array}$} & \multirow{21}{*}{$\begin{array}{l}\text { Layer } \\
\text { Moduli / } \\
\text { Thickness, } \\
\text { Poisson's } \\
\text { Ratio }\end{array}$} & HARP & - & $\begin{array}{l}\text { 3rd order } \\
\text { interp. }\end{array}$ & - & VG & $\begin{array}{c}\text { Khaz., Roes. } \\
97\end{array}$ \\
\hline & & $\begin{array}{l}\text { 20-28-2 MLP } \\
21-34-3 \text { MLP } \\
22-45-4 \text { MLP }\end{array}$ & - & - & $\begin{array}{l}1 \\
1 \\
1\end{array}$ & VG & $\begin{array}{c}\text { Kim \& Kim } \\
1998\end{array}$ \\
\hline & & $\begin{array}{c}6-60-60-2 \text { MLP } \\
12-60-60-1 \text { MLP }\end{array}$ & BP & - & $\begin{array}{l}5 \\
2 \\
\end{array}$ & VG & $\begin{array}{c}\text { Ceylan et al. } \\
2007 \\
\end{array}$ \\
\hline & & $x-[10,15]-x$ MLP & BP & Logistic & - & G & $\begin{array}{c}\text { Sharma, Das } \\
08 \\
\end{array}$ \\
\hline & & $\begin{array}{l}\text { 6-40-40-1 MLP } \\
\text { 8-40-40-1 MLP }\end{array}$ & BP & - & $\begin{array}{l}4 \\
3\end{array}$ & G & $\begin{array}{c}\text { Gopalakrishnan } \\
2008\end{array}$ \\
\hline & & 8-60-60-1 MLP & BP & - & 4 & VG & $\begin{array}{c}\text { Gopalakrishnan } \\
\text { \& Ceylan } 2008\end{array}$ \\
\hline & & $\begin{array}{l}\text { 8-60-60-1 MLP } \\
\text { 7-60-60-1 MLP }\end{array}$ & $\mathrm{BP}$ & - & $\begin{array}{l}4 \\
5\end{array}$ & VG & $\begin{array}{c}\text { Bayrak \& } \\
\text { Ceylan } 2008\end{array}$ \\
\hline & & $\begin{array}{l}6-4-1 \mathrm{MLP} \\
3-5-1 \mathrm{MLP}\end{array}$ & BP & $\begin{array}{c}\text { Logistic / } \\
\text { Linear }\end{array}$ & $\begin{array}{l}3 \\
6\end{array}$ & VG & Park et al. 2009 \\
\hline & & $\begin{array}{l}10-28-1 \mathrm{MLP} \\
13-25-1 \mathrm{MLP} \\
14-28-1 \mathrm{MLP} \\
15-30-1 \mathrm{MLP} \\
19-14-1 \mathrm{MLP}\end{array}$ & $\mathrm{BP}$ & - & - & G & $\begin{array}{c}\text { Abdallah \& } \\
\text { Nazarian } 2009\end{array}$ \\
\hline & & $\begin{array}{l}\text { 5-3-1 MLP } \\
\text { 5-6-1 MLP }\end{array}$ & $\mathrm{BP}$ & Logistic & $\begin{array}{l}2 \\
2 \\
\end{array}$ & VG & $\begin{array}{c}\text { Xiao \& } \\
\text { Amirkhan. } 2009 \\
\end{array}$ \\
\hline & & 7-6-6-1 MLP & - & Logistic & 2 & $\mathrm{G}$ & $\begin{array}{l}\text { Solanki et al. } \\
2009\end{array}$ \\
\hline & & $\begin{array}{c}\text { 7-1250-2-1 GRNN } \\
\text { 7-100-1 RBFNN } \\
\text { 7-6-6-1 MLP }\end{array}$ & - & - & 2 & $\mathrm{G}$ & $\begin{array}{l}\text { Zaman } \\
\text { et al. } 2010\end{array}$ \\
\hline & & 16-38-1 MLP & $\mathrm{BP}$ & Logistic & 2 & $\mathrm{G}$ & Kim et al. 2010 \\
\hline & & 3-2-1 MLP & LM & Hyp. Tg & 6 & VG & Kok et al. 2010 \\
\hline & & $\begin{array}{c}\text { 10-10-1 MLP } \\
\text { 9-9-1 MLP } \\
\text { 7-6-1 MLP }\end{array}$ & $\mathrm{BP}$ & $\begin{array}{l}\text { Hyp. Tg / } \\
\text { Logistic } \\
\text { Hyp. Tg / } \\
\text { Linear } \\
\text { Logistic / } \\
\text { Linear } \\
\end{array}$ & - & VG & $\begin{array}{c}\text { Nazzal \& Tatari } \\
2013\end{array}$ \\
\hline & & 8-20-20-1 MLP & LM & $\begin{array}{l}\text { Hyp. Tg / } \\
\text { Linear }\end{array}$ & 2 & $\mathrm{G}$ & $\begin{array}{l}\text { Singh et al. } \\
2013\end{array}$ \\
\hline & & 7-15-3 MLP & LM & - & 2 & VG & $\begin{array}{l}\text { Saltan et al. } \\
2013\end{array}$ \\
\hline & & 10-4-1 MLP & LM & Нyр. Tg & - & G & $\begin{array}{c}\text { Tarawneh \& } \\
\text { Nazzal } 2014\end{array}$ \\
\hline & & 15-9-1 MLP & $\mathrm{BP}$ & Logistic & 1 & $\mathrm{G}$ & Kim et al. 2014 \\
\hline & & 5-9-1 MLP & BFGS & $\begin{array}{l}\text { Logistic / } \\
\text { Linear }\end{array}$ & 3 & $\mathrm{G}$ & Pożarycki 2015 \\
\hline & & 13-20-20-3 MLP & BP & Hyp. Tg & 2 & VG & $\begin{array}{l}\text { Leiva -Villac. et } \\
\text { al. } 2016\end{array}$ \\
\hline
\end{tabular}


Abambres M, Ferreira A (2017). Application of ANN in Pavement Engineering: State-of-Art, hal-02066889

(C) 2017 by Abambres and Ferreira (CC BY 4.0)

Table 4. ANN features employed in pavement materials and design problems: stress, strain, deflections, creep, material physical properties and ESAL.

\begin{tabular}{|c|c|c|c|c|c|c|c|}
\hline \multirow[b]{2}{*}{ Field } & \multirow[b]{2}{*}{ Problem } & \multicolumn{4}{|c|}{ ANN Feature } & \multirow[b]{2}{*}{ Quality } & \multirow[b]{2}{*}{ Ref } \\
\hline & & Architecture & $\begin{array}{l}\text { Learn. } \\
\text { Alg. }\end{array}$ & $\begin{array}{l}\text { Hid./Out. } \\
\text { Transfer } \\
\text { Function }\end{array}$ & $10^{\frac{\log (\mathrm{LD})}{\mathrm{IV}}}$ & & \\
\hline \multirow{18}{*}{$\begin{array}{l}\text { Materials } \\
\text { and Pav. } \\
\text { Design }\end{array}$} & \multirow{12}{*}{$\begin{array}{c}\text { Stress, } \\
\text { Strain, } \\
\text { Deflections } \\
\& \\
\text { Creep }\end{array}$} & PC 5-3-2-1 MLP & Evolutionary & - & 2 & $\mathrm{G}$ & $\begin{array}{c}\text { Attoh-Okine } \\
\text { \& Fekpe } \\
1997\end{array}$ \\
\hline & & 5-15-15-10 MLP & $\mathrm{BP}$ & $\begin{array}{c}\text { Logistic / } \\
\text { Linear }\end{array}$ & 6 & $\mathrm{G}$ & $\begin{array}{c}\text { Meier et al. } \\
1997\end{array}$ \\
\hline & & 6-29-29-3 MLP & BP & Logistic & 6 & VG & $\begin{array}{l}\text { Ceylan et } \\
\text { al. } \\
1999\end{array}$ \\
\hline & & $\begin{array}{l}5-60-60-2 \text { MLP } \\
5-60-60-3 \text { MLP }\end{array}$ & BP & Logistic & 5 & VG & $\begin{array}{l}\text { Ceylan et } \\
\text { al. } 2005\end{array}$ \\
\hline & & $\begin{array}{l}11-20-6 \text { MLP } \\
\text { 15-20-6 MLP } \\
\text { 12-20-6 MLP }\end{array}$ & BP & $\begin{array}{l}\text { Hyp. Tg / } \\
\text { Linear }\end{array}$ & $\begin{array}{l}2 \\
2 \\
2 \\
\end{array}$ & VG & $\begin{array}{c}\text { Zofka \& Yut } \\
2012\end{array}$ \\
\hline & & $\begin{array}{c}\text { 7-9-1 MLP } \\
6-8-1 \text { MLP } \\
6-3-1 \text { MLP } \\
6-10-1 \text { MLP }\end{array}$ & LM & $\begin{array}{l}\text { Logistic / } \\
\text { Hyp. Tg }\end{array}$ & - & VG & $\begin{array}{l}\text { Tapkin et } \\
\text { al. } 2012\end{array}$ \\
\hline & & 7-15-4 MLP & LM & $\begin{array}{l}\text { Hyp. Tg / } \\
\text { Linear }\end{array}$ & 3 & VG & $\begin{array}{c}\text { Ghanizadh } \\
\text { \& Fakhri } \\
2014\end{array}$ \\
\hline & & 3-60-60-6 MLP & LM & Logistic & 35 & VG & $\begin{array}{c}\text { Ceyan et al. } \\
2014\end{array}$ \\
\hline & & $\begin{array}{l}\text { 4-3-2 MLP } \\
\text { 6-3-2 MLP } \\
\text { 6-3-2 MLP }\end{array}$ & $\mathrm{BP}$ & Нyp. Tg & $\begin{array}{l}4 \\
2 \\
2\end{array}$ & $\mathrm{G}$ & $\begin{array}{l}\text { Raab et al. } \\
\quad 2015\end{array}$ \\
\hline & & 8-12-7-6 MLP & - & - & 2 & $\mathrm{G}$ & Saleh 2015 \\
\hline & & 7-13-1 MLP & LM & - & 2 & VG & $\begin{array}{c}\text { Shafabakhs } \\
\text { h et al. } \\
2015\end{array}$ \\
\hline & & 5-4-1 MLP & Quasi - Newt & $\begin{array}{l}\text { Hyp. Tg / } \\
\text { Linear }\end{array}$ & 3 & $\mathrm{G}$ & $\begin{array}{l}\text { Plati et al. } \\
2016\end{array}$ \\
\hline & \multirow{5}{*}{$\begin{array}{l}\text { Material } \\
\text { Physical } \\
\text { Properties }\end{array}$} & 8-8-1 MLP & LM & $\begin{array}{l}\text { Hyp. Tg / } \\
\text { Linear }\end{array}$ & 2 & $\mathrm{G}$ & $\begin{array}{c}\text { Saffarzadeh } \\
\text { \& Heidarip. } \\
2009 \\
\end{array}$ \\
\hline & & 4-3-1 MLP & LM & Logistic & 4 & VG & $\begin{array}{l}\text { Xiao et al. } \\
2011\end{array}$ \\
\hline & & 4-25-25-1 MLP & BP & Нyp. Tg & 5 & $\mathrm{G}$ & $\begin{array}{c}\text { Abo- } \\
\text { Hashema } \\
2013\end{array}$ \\
\hline & & $\begin{array}{c}\text { 18-300-300-600-4 } \\
\text { MLP }\end{array}$ & LM & Нyp. Tg & 2 & $\mathrm{G}$ & $\begin{array}{c}\text { Ozturk \& } \\
\text { Kutay } 2014\end{array}$ \\
\hline & & 5-8-6-1 MLP & LM & Logistic & 3 & $\mathrm{G}$ & $\begin{array}{c}\text { Specht \& } \\
\text { Khatchat. } \\
2014 \\
\end{array}$ \\
\hline & ESAL & 7-20-2 MLP & BP & Logistic & 2 & VG & $\begin{array}{l}\text { Tigdemir } \\
2014\end{array}$ \\
\hline
\end{tabular}




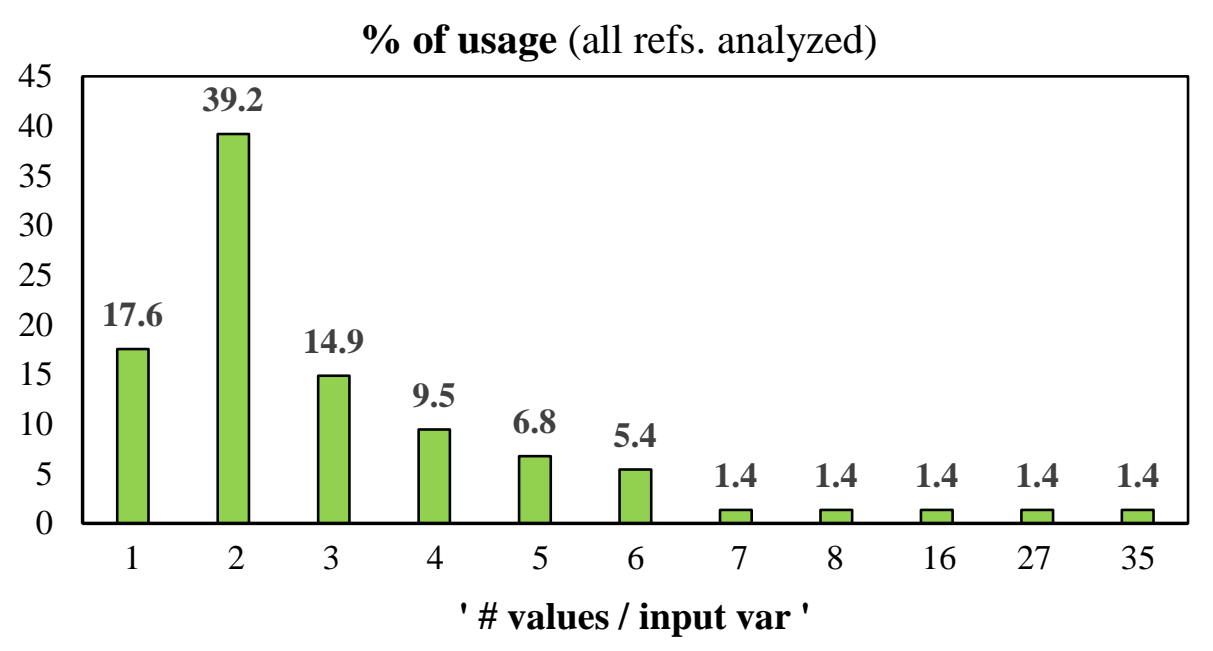

Fig. 18. Fictitious number of values per input variable according to the amount of learning data.

\section{Final Remarks}

An extensive state-of-the-art application of ANN in pavement engineering has been presented, which has covered fields such as pavement (i) management and (ii) materials and design. This work intends to motivate and support the related expert community in the use of neural nets in problems where there is abundant data but the solving methods usually adopted are too lengthy and/or inaccurate. A graphical insight of the usage frequency of the main ANN features in pavement (i) management (distresses excluded), (ii) distresses and (iii) materials and design problems, is presented. Lastly, it should be noted that despite the great amount of applications and quite satisfactory results found in the literature, there is a lack of utilization of more advanced techniques in the design of ANNs - in most cases, the more traditional architecture (MLP) and learning algorithms (BP, LM) were employed, and not much reference was made to special trimming and data preprocessing techniques for the improvement of the 
Abambres M, Ferreira A (2017). Application of ANN in Pavement Engineering: State-of-Art, hal-02066889

(C) 2017 by Abambres and Ferreira (CC BY 4.0)

network generalization ability. The authors of this paper are currently working to make a contribution to change this scenario in the near future.

\section{Acknowledgements}

The present research work has been carried out in the framework of project PAVENERGY - Pavement Energy Harvest Solutions (PTDC/ECM-TRA/3423/2014), co-financed by the European Regional Development Fund (POCI-01-0145-FEDER-016676) through the Operational Program for Competitiveness Factors (COMPETE) and by national funds through the Portuguese Foundation for Science and Technology (FCT).

\section{References}

Abdallah IN, Nazarian S (2009). Rapid Interpretation of Nondestructive Testing Results using Neural Networks, In: Intelligent and Soft Computing in Infrastructure Systems Engineering - Recent Advances, K Gopalakrishnan, H Ceylan and N Attoh-Okine (eds), 1st edition, Springer Berlin, 1-19.

Abdelrahim A, George K (2000). Artificial Neural Network for Enhancing Selection of Pavement Maintenance Strategy, Transportation Research Record, 1699(1), 16-22.

Abo-Hashema M (2013). Modeling Pavement Temperature Prediction using Artificial Neural Networks, In: 2013 Airfield \& Highway Pavement Conference: Sustainable and Efficient Pavements, Los Angeles, California, June 9-12, Imad L. Al-Qadi, Scott Murrell (eds), 490-505.

Adeli H (2001). Neural networks in civil engineering: 1989-2000, Computer-Aided Civil and Infrastructure Engineering, 16(2), 126-142.

Adeli H, Yeh C (1989). Perceptron Learning in Engineering Design, Computer-Aided Civil and Infrastructure Engineering, 4(4), 247-256.

Akgüngör A, Doğan E (2009). An artificial intelligent approach to traffic accident estimation: Model development and application, Transport, 24(2), 135-142.

Al-Alawi S, Ali G, Bakheit C (1996). A novel approach for traffic accident analysis and prediction using artificial neural networks, Road \& Transport Research, 5(2), 118-33.

Alkheder S, Taamneh M, Taamneh S (2016). Severity Prediction of Traffic Accident Using an Artificial Neural Network, Journal of Forecasting, 36(1), 100-108.

Alsugair AM, Al-Qudrah AA (1998). Artificial Neural Network Approach for Pavement Maintenance, Journal of Computing in Civil Engineering, 12(4), 249-255.

Amin S, Amador-Jiménez L (2016). Backpropagation Neural Network to estimate pavement performance: 
Abambres M, Ferreira A (2017). Application of ANN in Pavement Engineering: State-of-Art, hal-02066889

(C) 2017 by Abambres and Ferreira (CC BY 4.0)

dealing with measurement errors, Road Materials and Pavement Design, 1-21, DOI: 10.1080/14680629.2016.1202129

Attoh-Okine N (2001). Grouping pavement condition variables for performance modeling using selforganizing maps, Computer-Aided Civil and Infrastructure Engineering, 16(2), 112-125.

Attoh-Okine N, Fekpe E (1996). Strength characteristics modeling of lateritic soils using adaptive neural networks, Construction and Building Materials, 10(8), 577-582.

Azoff EM (1994). Neural Network Time Series Forecasting of Financial Markets. John Wiley and Sons, Chichester.

Banan M, Hjelmstad (1996). Neural Networks and AASHO Road Test, Journal of Transportation Engineering, 122(5), 358-366.

Barba L, Rodríguez N, Montt C (2014). Smoothing Strategies Combined with ARIMA and Neural Networks to Improve the Forecasting of Traffic Accidents, The Scientific World Journal, 2014, 1-12.

Basheer I, Hajmeer M (2000). Artificial neural networks: Fundamentals, computing, design, and application, Journal of Microbiological Methods, 43(1), 3-31.

Bayrak M, Ceylan H (2008). Neural Network-Based Approach for Analysis of Rigid Pavement Systems Using Deflection Data, Transportation Research Record: Journal of the Transportation Research Board, 2068, 61-70.

Bellman RE (1978). An Introduction to Artificial Intelligence: Can Computers Think?, Boyd \& Fraser Publishing Company, San Francisco.

Bosurgi G, Trifirò F (2005). A model based on artificial neural networks and genetic algorithms for pavement maintenance management, International Journal of Pavement Engineering, 6(3), 201-209.

Can Yilmaz A, Aci C, Aydin K (2016). Traffic accident reconstruction and an approach for prediction of fault rates using artificial neural networks: A case study in Turkey, Traffic Injury Prevention, 17(6), 585-589.

Ceylan H, Bayrak M, Gopalakrishnan K (2014). Neural Networks Applications in Pavement Engineering: A Recent Survey, International Journal of Pavement Research and Technology, 7(6), 434-444.

Ceylan H, Gopalakrishnan K (2014). Finite Element based Hybrid Evolutionary Optimization Approach to Solving Rigid Pavement Inversion Problem. Engineering with Computers, 30, 1-13.

Ceylan H, Gopalakrishnan K, Guclu A (2007). Advanced Approaches to Characterizing Nonlinear Pavement System Responses, Transportation Research Record, No. 2005, 86-94.

Ceylan H, Gopalakrishnan K, Lytton R (2011). Neural Networks Modeling of Stress Growth in Asphalt Overlays due to Load and Thermal Effects during Reflection Cracking, Journal of Materials in Civil Engineering, 23(3), 221-229.

Ceylan H, Guclu A, Tutumluer E, Thompson M (2005). Backcalculation of full-depth asphalt pavement layer moduli considering nonlinear stress-dependent subgrade behavior, International Journal of Pavement Engineering, 6(3), 171-182.

Ceylan H, Tutumluer E, Barenberg E (1999). Artificial Neural Networks for Analyzing Concrete Airfield Pavements Serving the Boeing B-777 Aircraft, Transportation Research Record: Journal of the Transportation Research Board, 1684, 110-117.

Choi J, Adams TM, Bahia HU (2004). Pavement roughness modeling using back-propagation neural networks, Computer-aided Civil and Infrastructure Engineering, 19(4), 295-303.

Dougherty M (1995). A review of neural networks applied to transport, Transportation Research Part C: Emerging Technologies, 3(4), 247-260.

Du K-L, Swamy MNS. (2014). Neural Networks and Statistical Learning, Springer-Verlag, London.

Eldin N, Senouci A (1995a). A Pavement Condition-Rating Model Using Backpropagation Neural Networks, Computer-Aided Civil and Infrastructure Engineering, 10(6), 433-441. 
Abambres M, Ferreira A (2017). Application of ANN in Pavement Engineering: State-of-Art, hal-02066889

(C) 2017 by Abambres and Ferreira (CC BY 4.0)

Eldin N, Senouci A (1995b). Use of neural networks for condition rating of jointed concrete pavements, Advances in Engineering Software, 23(3), 133-141.

Flintsch G, Chen C (2004). Soft Computing Applications in Infrastructure Management, Journal of Infrastructure Systems, 10(4), 157-166.

Flintsch G, Zaniewski J, Delton J (1996). Artificial Neural Network for Selecting Pavement Rehabilitation Projects, Transportation Research Record: Journal of the Transportation Research Board, 1524, 185-193.

Flood I (2008). Towards the next generation of artificial neural networks for civil engineering, Advanced Engineering Informatics, 22(1), 4-14.

Flood I, Kartam N (1994a). Neural Networks in Civil Engineering: I-Principals and Understanding, Journal of Computing in Civil Engineering, 8(2), 131-148.

Fonseca ET, Vellasco PCGS, Andrade SAL, Vellasco MMBR (2003). Neural network evaluation of steel beam patch load capacity, Advances in Engineering Software, 34(11-12), 763-772.

Fwa TF, Chan WT (1993). Priority rating of highway maintenance needs by neural networks, Journal of Transportation Engineering, 119(3), 419-432.

Gajewski J, Sadowski T (2014). Sensitivity analysis of crack propagation in pavement bituminous layered structures using a hybrid system integrating Artificial Neural Networks and Finite Element Method, Computational Materials Science, 82(February), 114-117.

Ghanizadeh AR, Fakhri M (2014). Prediction of frequency for simulation of asphalt mix fatigue tests using MARS and ANN, The Scientific World Journal, 2014, 1-16.

Gholizadeh S, Pirmoz A, Attarnejad R (2011). Assessment of load carrying capacity of castellated steel beams by neural networks, Journal of Constructional Steel Research, 67(5), 770-779.

Gopalakrishnan K (2008). Evaluation of accelerated deterioration in NAPTF flexible test pavements, Journal of Zhejiang University-SCIENCE A, 9(9), 1157-1166.

Gopalakrishnan K, Ceylan H (2008). Stiffness characterization of full-scale airfield test pavements using computational intelligence techniques, The IES Journal Part A: Civil \& Structural Engineering, 1(4), 280-290.

Hajek J, Hurdal B (1993). Comparison of Rule-Based and Neural Network Solutions for a Structured Selection Problem, Transportation Research Record, 1399, 1-7.

Haykin SS (2009). Neural networks and learning machines, Prentice Hall/Pearson, NY.

He J, Qi Z, Hang W, Zhao C, King M (2014). Predicting freeway pavement construction cost using a backpropagation neural network: a case study in Henan, China, The Baltic Journal of Road and Bridge Engineering, 9(1), 66-76.

Hern A (2016). Google says machine learning is the future. So I tried it myself, Available at: www.theguardian.com/technology/2016/jun/28/all (Accessed: 2 November 2016).

Hertzmann A, Fleet D (2012). Machine Learning and Data Mining, Lecture Notes CSC 411/D11, Computer Science Department, University of Toronto, Canada.

Huang G, Chen L, Siew C (2006b). Universal approximation using incremental constructive feedforward networks with random hidden nodes, IEEE transactions on neural networks, 17(4), 879-92.

Huang G-B, Chen L (2007). Convex incremental extreme learning machine, Neurocomputing, 70(16-18), 3056-3062.

Huang G-B, Zhou H, Ding X, Zhang R (2011). Extreme learning machine for regression and multiclass classification, IEEE Transactions on systems, man and cybernetics - part B: cybernetics, 42(2), 513-529.

Huang G-B, Zhu Q-Y, Siew C-K (2006a). Extreme learning machine: Theory and applications, Neurocomputing, 70(1-3), 489-501.

Jorge D, Ferreira A (2012). Road network pavement maintenance optimization using the HDM4 pavement 
Abambres M, Ferreira A (2017). Application of ANN in Pavement Engineering: State-of-Art, hal-02066889

(C) 2017 by Abambres and Ferreira (CC BY 4.0)

performance prediction models, International Journal of Pavement Engineering, 13(1), 39-51.

Kaseko M, Ritchie S (1993). A neural network-based methodology for pavement crack detection and classification, Transportation Research Part C: Emerg. Tech., 1(4), 275-91.

Khazanovich L, Roesler J (1997). DIPLOBACK: Neural-Network-Based Backcalculation Program for Composite Pavements, Transportation Research Record: Journal of the Transportation Research Board, $1570,143-150$

Kim D, Kim J, Mun S (2010). Normalization methods on neural networks for predicting pavement layer moduli, Road \& Transport Research, 19(3), 38-46.

Kim S, Gopalakrishnan K, Ceylan H (2009). Neural Networks Application in Pavement Infrastructure Materials, In: Intelligent and Soft Computing in Infrastructure Systems Engineering - Recent Advances, K Gopalakrishnan, H Ceylan and N Attoh-Okine (eds), 1st edition, Springer Berlin, 47-66.

Kim S, Yang J, Jeong J (2014). Prediction of subgrade resilient modulus using artificial neural network, KSCE Journal of Civil Engineering, 18(5), 1372-1379.

Kim Y, Kim YR (1998). Prediction of layer moduli from falling weight deflectometer and surface wave measurements using artificial neural network, Transportation Research Record, No. 1639, 53-61.

Kok B, Yilmaz M, Sengoz B, Sengur A, Avci E. (2010). Investigation of complex modulus of base and SBS modified bitumen with artificial neural networks, Expert Systems with Applications, 37(12), 7775-7780.

Lee BJ, Lee H (2004). Position-Invariant Neural Network for Digital Pavement Crack Analysis, ComputerAided Civil and Infrastructure Engineering, 19(2), 105-118.

Leiva-Villacorta F, Vargas-Nordcbeck A, Timm D (2016). Non-destructive evaluation of sustainable pavement technologies using artificial neural networks, International Journal of Pavement Research and Technology, in press (DOI: 10.1016/j.ijprt.2016.11.006).

Liang N, Huang G, Saratchandran P, Sundararajan N (2006). A fast and accurate online Sequential learning algorithm for Feedforward networks, IEEE Transactions on Neural Networks, 17(6), 1411-23.

May R, Dandy G, Maier H (2011). Review of Input Variable Selection Methods for Artificial Neural Networks, Artificial Neural Networks - Methodological Advances and Biomedical Applications, Kenji Suzuki (Ed.), InTech, DOI: 10.5772/16004.

McCulloch WS, Pitts W (1943). A logical calculus of the ideas immanent in nervous activity, Bulletin of Mathematical Biophysics, 5(4), 115-133.

Mei X, Gunaratne M, Lu J, Dietrich B (2004). Neural Network for Rapid Depth Evaluation of Shallow Cracks in Asphalt Pavements, Computer-Aided Civil and Infrastructure Engineering, 19(3), 223-230.

Meier R, Alexander D, Freeman R. (1997). Using Artificial Neural Networks as a Forward Approach to Backcalculation, Transportation Research Record: Journal of the Transportation Research Board, 1570, 126-133.

Miche Y, Sorjamaa A, Bas P, Simula O, Jutten C, Lendasse A (2010). OP-ELM: Optimally pruned extreme learning machine, IEEE Transactions on Neural Networks, 21(1), 158-62.

Min J, Park S, Yun C-B, Lee C-G (2012). Impedance-based structural health monitoring incorporating neural network technique for identification of damage type and severity, Engineering Structures, 39(June), 210-220.

Mosa A, Rahmat R, Ismail A, Taha M (2013). Expert System to Control Construction Problems in Flexible Pavements, Computer-Aided Civil and Infrastructure Engineering, 28(4), 307-323.

Mozer MC, Smolensky P (1989). Skeletonization: a technique for trimming the fat from a network via relevance assessment, Advances in neural information processing systems, Morgan Kaufmann Publishers Inc., San Francisco, CA, USA, 1, 107-115.

Nazzal M, Tatari O (2013). Evaluating the use of neural networks and genetic algorithms for prediction of subgrade resilient modulus, International Journal of Pavement Engineering, 14(4), 364-373. 
Abambres M, Ferreira A (2017). Application of ANN in Pavement Engineering: State-of-Art, hal-02066889

(C) 2017 by Abambres and Ferreira (CC BY 4.0)

NCHRP (2004). Guide for Mechanistic-Empirical Design of New and Rehabilitated Pavement Structures, NCHRP 1-37A Final Report, Champaign, IL. Available URL [Access March 8th, 2017].

Ngwangwa H, Heyns P, Breytenbach H, Els P (2014). Reconstruction of road defects and road roughness classification using Artificial Neural Networks simulation and vehicle dynamic responses: Application to experimental data, Journal of Terramechanics, 53(June), 1-18.

Oeser M, Freitag S (2016). Fractional derivatives and recurrent neural networks in rheological modelling part I: Theory, International Journal of Pavement Engineering, 17(2), 87-102

Olden JD, Jackson DA (2002). Illuminating the "black box": a randomization approach for understanding variable contributions in artificial neural networks, Ecological Modelling, 154(1-2), 135-150.

Owusu-Ababio S (1995). Modeling skid resistance for flexible pavements: a comparison between regression and neural network models, Transportation Research Record, No. 1501, 60-71.

Owusu-Ababio S (1998). Effect of Neural Network Topology on Flexible Pavement Cracking Prediction, Computer-Aided Civil and Infrastructure Eng, 13(5), 349-355.

Ozturk HI, Kutay ME (2014). An artificial neural network model for virtual Superpave asphalt mixture design, Int. J. Pavement Eng., 15(2), 151-162.

Pant P, Zttou X, Arudi R, Bodocsi A, Emin Aktan A (1993). Neural-Network-Based Procedure for Condition Assessment of Utility Cuts in Flexible Pavements, Transportation Research Record, 1399, 8-13.

Papadrakakis M, Lagaros ND (2016). Reliability-based structural optimization using neural networks and Monte Carlo simulation, Computer Methods in Applied Mechanics and Engineering, 191(32), 3491-3507.

Park H, Kweon G, Lee S (2009). Prediction of Resilient Modulus of Granular Subgrade Soils and Subbase Materials using Artificial Neural Network, Road Materials and Pavement Design, 10(3), 647-665.

Plati C, Georgiou P, Papavasiliou V (2016). Simulating pavement structural condition using artificial neural networks, Structure and Infrastructure Engineering, 12(9), 1127-36.

Poole D, Mackworth AK, Goebel R (1998). Computational intelligence: A logical approach, Oxford University Press, Oxford.

Pożarycki A (2015). Pavement diagnosis accuracy with controlled application of artificial neural network, The Baltic Journal of Road and Bridge Engineering, 10(4), 355-364.

Prasath R, O’Reilly P, Kathirvalavakumar T (2014). Mining Intelligence and Knowledge Exploration, 1st ed, Springer International Publishing, Switzerland, 82-90.

Prieto A, Prieto B, Ortigosa EM, Ros E, Pelayo F, Ortega J, Rojas I (2016). Neural networks: An overview of early research, current frameworks and new challenges, Neurocomputing, 214(November), 242-268.

Raab C, Grenfell J, Abd El Halim AO, Partl MN (2015). The influence of age on interlayer shear properties, Int Journal of Pavement Engineering, 16(6), 559-569.

Rafiq M, Bugmann G, Easterbrook D (2001). Neural network design for engineering applications, Computers \& Structures, 79(17), 1541-1552

Reed R (1993). Pruning algorithms-a survey, IEEE Transactions Neural Net, 4(5), 740-7.

Rich E, Knight K (1991). Artificial Intelligence (second edition), McGraw-Hill, NY.

Roberts C, Attoh-Okine N (1998). A Comparative Analysis of Two Artificial Neural Networks Using Pavement Performance Prediction, Computer-Aided Civil and Infrastructure Engineering, 13(5), 339-348.

Russell SJ, Norvig P (2010). Artificial intelligence: a modern approach (third edition), Prentice-Hall, Upper Saddle River.

Saffarzadeh M, Heidaripanah A (2009) Effect of Asphalt Content on the Marshall Stability of Asphalt Concrete Using Artificial Neural Networks, Scientia Iranica Transaction a-Civil Engineering, 16(1), 98-105. 
Abambres M, Ferreira A (2017). Application of ANN in Pavement Engineering: State-of-Art, hal-02066889

(C) 2017 by Abambres and Ferreira (CC BY 4.0)

Saghafi B, Hassani A, Noori R, Bustos MG (2009). Artificial neural networks and regression analysis for predicting faulting in jointed concrete pavements considering base condition, International Journal of Pavement Research and Technology, 2(1), 20-25.

Saleh M (2015). Prediction of Rigid Pavement Responses under Axle Loads Using Artificial Neural Network, International Journal of Pavement Research and Technology, 8(1), 10-16.

Saltan M, Uz VE, Aktas B (2013). Artificial neural networks-based backcalculation of the structural properties of a typical flexible pavement, Neural Computing and Applications, 23(6), 1703-1710.

Santos J, Ferreira A (2012). Pavement design optimization considering costs and preventive interventions, Journal of Transportation Engineering, American Society of Civil Engineers, 138(7), 911-923.

Santos J, Ferreira A, Flintsch G (2017). An adaptive hybrid genetic algorithm for pavement management, International Journal of Pavement Engineering, in press (doi: 10.1080/10298436.2017.1293260)

Scott (2016). The future of coding, artificial intelligence and neural networks, Available at: www.startcode.net/blog/the-future-of-coding-and-artificial-intelligence (Accessed: 2 November 2016).

Shafabakhsh G, Talebsafa M, Motamedi M, Badroodi S (2015). Analytical evaluation of load movement on flexible pavement and selection of optimum neural network algorithm, KSCE Journal of Civil Engineering, 19(6), 1738-1746.

Sharifi Y, Tohidi S (2014b). Lateral-torsional buckling capacity assessment of web opening steel girders by artificial neural networks - elastic investigation, Frontiers of Structural and Civil Engineering, 8(2), $167-177$.

Sharma S, Das A (2008). Backcalculation of pavement layer moduli from falling weight deflectometer data using an artificial neural network, Canadian Journal of Civil Engineering, 35(1), 57-66.

Sheidaii MR, Bahraminejad R (2012). Evaluation of compression member buckling and post-buckling behavior using artificial neural network, Journal of Constructional Steel Research, 70(March), 71-77.

Singh D, Zaman M, Commuri S (2013). Artificial Neural Network Modeling for Dynamic Modulus of Hot Mix Asphalt Using Aggregate Shape Properties, Journal of Materials in Civil Engineering, 25(1), 54-62.

Solanki P, Zaman M, Ebrahimi A (2009). Regression and Artificial Neural Network Modeling of Resilient Modulus of Subgrade Soils for Pavement Design Applications, In: Intelligent and Soft Computing in Infrastructure Systems Engineering - Recent Advances, K Gopalakrishnan, H Ceylan and N AttohOkine (eds), 1st edition, Springer Berlin, 269-304.

Solhmirzaei A, Azadi S, Kazemi R (2012). Road profile estimation using wavelet neural network and 7DOF vehicle dynamic systems, Journal of Mechanical Science and Technology, 26(10), 3029-3036.

Specht L, Khatchatourian O (2014). Application of artificial intelligence to modelling asphalt-rubber viscosity, International Journal of Pavement Engineering, 15(9), 799-809.

Tabatabaee N, Ziyadi M, Shafahi Y (2013). Two-Stage Support Vector Classifier and Recurrent Neural Network Predictor for Pavement Performance Modeling, Journal of Infrastructure Systems, 19(3), 266-274.

Tapkın S, Çevik A, Özcan Ş (2012). Utilizing Neural Networks and Closed Form Solutions to Determine Static Creep Behaviour and Optimal Polypropylene Amount in Bituminous Mixtures, Materials Research, 15(6), 865-883.

Tarawneh B, Nazzal MD (2014). Optimization of resilient modulus prediction from FWD results using artificial neural network, Periodica Polytechnica, 58(2), 143-154.

Terzi S (2007). Modeling the pavement serviceability ratio of flexible highway pavements by artificial neural networks, Construction and Building Materials, 21(3), 590-593.

Thube DT (2012). Artificial Neural Network (ANN) Based Pavement Deterioration Models for Low Volume Roads in India, International Journal of Pavement Research and Technology, 5(2), 115-120.

Tiğdemir M (2014). Re-Evaluation of the AASHTO-Flexible Pavement Design Equation with Neural Network Modeling, PLoS ONE, 9(11), p.e113226. 
Abambres M, Ferreira A (2017). Application of ANN in Pavement Engineering: State-of-Art, hal-02066889

(C) 2017 by Abambres and Ferreira (CC BY 4.0)

Weigend AS, Rumelhart DE, Huberman BA (1991). Generalization by weight-elimination applied to currency exchange rate prediction, Proc. Int. Joint Conf. Neural Networks, 18-21 Nov., Singapore, IEEE (ed.), vol. I, 837-841.

Wilamowski BM, Irwin JD (2011). The industrial electronics handbook: Intelligent Systems, CRC Press, Boca Raton.

Wilamowski BM, Yu H (2010a). Improved Computation for Levenberg-Marquardt Training, IEEE Transactions on Neural Networks, 21(6), 930-937.

Wilamowski BM, Yu H (2010b). Neural network learning without backpropagation, IEEE Transactions on Neural Networks, 21(11), 1793-1803.

Winston PH (1992). Artificial Intelligence ( $3^{\text {rd }}$ ed), Addison-Wesley, Reading, MA.

Woods WA (1986). Important issues in knowledge representation, Proceedings of the Institute of Electrical and Electronics Engineers, 74(10), 1322-34.

Wu Z, Hu S, Zhou F (2014). Prediction of stress intensity factors in pavement cracking with neural networks based on semi-analytical FEA, Expert Systems with Applications. 41(4), 1021-1030.

Xiao F, Amirkhanian S (2009). Artificial Neural Network Approach to Estimating Stiffness Behavior of Rubberized Asphalt Concrete Containing Reclaimed Asphalt Pavement, Journal of Transportation Engineering, 135(8), 580-589.

Xiao F, Putman B, Amirkhanian S (2011). Viscosity prediction of CRM binders using artificial neural network approach, International Journal of Pavement Engineering, 12(5), 485-495.

Yildirim S, Uzmay I (2001). Statistical analysis of vehicles' vibration due to road roughness using radial basis artificial neural network, Applied Artificial Intelligence, 15(4), 419-427.

Yoo H, Kim Y (2016). Development of a crack recognition algorithm from non-routed pavement images using artificial neural network and binary logistic regression, KSCE Journal of Civil Engineering, 20(4), 1151-1162.

Yousefzadeh M, Azadi S, Soltani A (2010). Road profile estimation using neural network algorithm, Journal of Mechanical Science and Technology, 24(3), 743-754.

Zaman M, Solanki P, Ebrahimi A, White L (2010). Neural Network Modeling of Resilient Modulus Using Routine Subgrade Soil Properties, International Journal of Geomechanics, 10(1), 1-12.

Ziari H, Sobhani H, Ayoubinejad J, Hartmann T (2016). Prediction of IRI in short and long terms for flexible pavements: ANN and GMDH methods, International Journal of Pavement Engineering, 17(9), 776-788.

Zofka A, Yut I (2012). Prediction of Asphalt Creep Compliance Using Artificial Neural Networks, Archives of Civil Engineering, 58(2), 153-173.

(C) 2017 by Abambres and Ferreira. Open access publication under the terms and conditions of the Creative Commons Attribution 4.0 (CC BY 4.0) license (http://creativecommons.org/licenses/by/4.0) 